\title{
Unravelling Degradation Pathways of Oxide-supported Pt Fuel Cell Nanocatalysts under in situ Operating Conditions
}

Henrike Schmies ${ }^{1}$, Arno Bergmann ${ }^{1}$, Jakub Drnec ${ }^{2}$, Guanxiong Wang $^{3}$, Detre Teschner ${ }^{4,5}$, Stefanie Kühl ${ }^{1}$, Daniel Sandbeck ${ }^{6}$, Serhiy Cherevko ${ }^{6}$, Martin Gocyla ${ }^{7}$, Meital Shviro ${ }^{7}$, Marc Heggen $^{7}$, Vijay Ramani ${ }^{3}$, Rafal Dunin-Borkowski ${ }^{7}$, Karl J.J. Mayrhofer ${ }^{6}$, Peter Strasser $^{*}{ }^{*}$

${ }^{1}$ Department of Chemistry, Chemical Engineering Division, Technical University of Berlin, Berlin, Germany

${ }^{2}$ European Synchrotron Radiation Facility (ESRF), Grenoble, France

${ }^{3}$ School of Engineering \& Applied Science, Washington University in St. Louis, St. Lois, USA

${ }^{4}$ Department of Heterogeneous Reactions, Max-Planck-Institute for Chemical Energy Conversion, Mühlheim an der Ruhr, Germany

${ }^{5}$ Department of Inorganic Chemistry, Fritz-Haber-Institut der Max-Planck-Gesellschaft, Berlin, Germany

${ }^{6}$ Helmholtz-Institute Erlangen-Nürnberg for Renewable Energy (IEK-11), Forschungszentrum Jülich, Erlangen, Germany

${ }^{7}$ Ernst-Ruska Centre for Microscopy and Spectroscopy with Electrons and Peter Grünberg Institute, Forschungszentrum Jülich, Jülich, Germany

*Email: pstrasser@tu-berlin.de

Keywords: oxide supported platinum, oxygen reduction reaction, nanoparticle, in situ X-ray, catalyst degradation 


\section{WILEY-VCH}

\section{Abstract}

Knowledge of degradation pathways of catalyst/support material couples aids the development of rational strategies to improve their stability. Here, this is exemplified using oxide-supported Platinum nanoparticles designed as electrocatalysts for the oxygen reduction reaction (ORR) at fuel cell cathodes. The structural and morphological evolution of homogeneously distributed indium tin oxide (ITO)-supported Pt nanoparticles with welldefined size is investigated under simulated fuel cell operating conditions. Degradation protocols mimic fuel cell operating conditions during regular and demanding start-up/shutdown regimes. The evolution of crystal structure, composition, crystallite and particle size distribution is tracked by in situ high energy X-ray techniques, metal dissolution by in situ scanning flow cell coupled with mass spectrometry (SFC-ICP-MS) and Pt surface morphology by advanced electron microscopy. In the regular life-time regime, Pt degradation in the form of particle growth, agglomeration and dissolution or detachment could be unambiguously excluded as mechanisms of catalytic ORR activity losses. Here, Pt poisoning appears likely as the origin of the observed activity loss, while in the start-up regime degradation is suppressed and only minor losses in catalytic activity are observed. The results show that oxide supported Pt electrocatalysts excel by nanoparticle stabilization and corrosion resistance of the oxide support but suffer strongly from Pt surface modifications by deposition of sub-monolayers of metal ions from the support. Thus, the elucidation of degradation pathways of oxide supported Pt nanoparticles leads to an enhanced understanding in cathode electrocatalysts for polymer electrolyte fuel cells (PEFC). 


\section{WILEY-VCH}

\section{Introduction}

Polymer electrolyte fuel cells (PEFC) offer great possibilities as clean energy conversion devices. However, there are still some major issues that need to be solved for a wide commercialization of PEFCs such as the catalyst stability at the cathode side where the oxygen reduction reaction (ORR) takes place.

Carbon supported Pt based materials are state-of-art electrocatalysts but they suffer from several degradation phenomena especially during fuel cell start-stop procedure that come along with harsh conditions (low $\mathrm{pH}$, high potentials, elevated temperatures). ${ }^{[1]}$ Activity degradation mainly arises from Pt dissolution, Ostwald ripening and/or carbon corrosion. ${ }^{[2-4]}$ Several attempts have been made to enhance the overall catalyst stability on the cathode site. ${ }^{[5]}$ For example, alloying the Pt nanoparticles with one or more transition metals like Ni not only improves the Pt mass based activity ${ }^{[6]}$ but also increases the catalyst stability. ${ }^{[7]}$ However, to completely prevent carbon corrosion alternative support materials for fuel cell catalysts were investigated in the past decade. Metal oxides have recently gained attention in this field because they offer a variety of features required for a stable electrocatalyst for oxygen reduction. ${ }^{[8]}$ Essential properties are physical high surface area, high electrical conductivity, thermal stability and above all their corrosion resistance. Therefore, several metal oxides have been investigated: Popov et al. showed that $\mathrm{Pt}$ on $\mathrm{TiO}_{2}$ has a high stability towards ORR caused by the high corrosion resistance and the strong metal support interaction (SMSI). ${ }^{[9]}$ This SMSI effect was further analyzed by Alonso-Vante et al. ${ }^{[10]}$, they were able to show changes in the local electron density of Pt when deposited on titanium oxide-carbon and tungsten oxide-carbon support. By X-ray photoelectron spectroscopy (XPS) analysis they saw an increase in the asymmetry of the Pt $4 \mathrm{f}$ peak which the authors attributed to either an alloy formation between Pt and the support or a partial charge transfer from the support to Pt. Furthermore, a Molybdenum-doped $\mathrm{Ti}$ dioxide was found to be a stable electrocatalyst 


\section{WILEY-VCH}

because of electronic structure changes in the Pt upon synergistic interaction with the support material. ${ }^{[1]}$ A similar phenomenon was observed for $\mathrm{Pt} / \mathrm{Ta} 0.3 \mathrm{Ti}_{0.7} \mathrm{O}_{2}$ where the electrochemical surface area (ECSA) decreased less compared to $\mathrm{Pt} / \mathrm{C}$ reference catalyst when exposed to accelerated load cycling test designed to test the electrocatalyst stability. ${ }^{[12,13]}$ The catalyst exhibits good activity when tested in an operating fuel cell and exceptional catalytic stability after 10000 cycles of a simulated start-up/shut-down stress test. The superior catalyst stability was explained with a lower Pt dissolution rate compared to carbon supported Pt electrocatalyst and the SMSI between Pt nanoparticles and $\mathrm{Ta}_{0.3} \mathrm{Ti}_{0.7} \mathrm{O}_{2}$. Another class of stable carbon-free supports was found to be $\mathrm{RuO}_{2} / \mathrm{TiO}_{2}$ and $\mathrm{RuO}_{2} / \mathrm{SiO}_{2}$. ${ }^{[14]}$ These materials offer a conductivity and surface area comparable to mesoporous carbon, a promising electrochemical stability against aggressive accelerated test protocols besides improved membrane electrode assembly (MEA) performance. The incorporation of Pt nanoparticles with a well-defined size into the electrodes to decrease Ohmic and transport losses has to be improved to make it a viable alternative in automotive application. Furthermore, Dou et al. reported on tin oxide as another candidate for carbon free support in PEFCs. ${ }^{[15]}$ The material retained $27 \%$ of its initial ECSA when the $\mathrm{Pt} / \mathrm{C}$ reference catalyst shows no more surface area after 2000 cycles. ${ }^{[15]}$ In another approach, Tsukatsune et al found that their $\mathrm{Pt} / \mathrm{SnO}_{2}$ and $\mathrm{Pt} / \mathrm{Nb}-\mathrm{SnO}_{2}$ electrocatalysts suffer from low specific surface area accompanied with low specific activity. ${ }^{[16]}$ Cognard et al. investigated antimony-doped tin oxide (ATO) supported Pt electrocatalyst as cathode material for PEFC. ${ }^{[17]}$ The harsh AST conditions of potential jumps between 1.0 and $1.5 \mathrm{~V}$ lead to depletion of $\mathrm{Sb}$ atoms from the support surface and a decreased conductivity and hence to a loss in catalytic activity.

Indium tin oxide (ITO) offers several advantages in regard to the conditions that are present in the environment of fuel cell catalysts at the cathode site such as low $\mathrm{pH}$, high temperatures and high potentials. Additionally, ITO has the advantage of low electrical resistance. Pt/ITO catalyst systems have been tested as alternative material to conventional Pt nanoparticles 


\section{WILEY-VCH}

dispersed on high surface area carbon. Liu et al. showed that a Pt/ITO ORR electrocatalyst offered activity as well as enhanced stability during an AST. ${ }^{[18,19]}$ These Pt nanoparticles were deposited on the ITO via a galvanic displacement of a $\mathrm{Cu}$ monolayer from a $\mathrm{K}_{2} \mathrm{PtCl}_{4}$ precursor. While the authors did not provide evidence for a complete displacement or removal of contaminating $\mathrm{Cu}$ residues, their data suggested that the enhanced ORR activity is caused by synergistic effects between surface Sn and Pt. ${ }^{[19]}$ A recent XPS study by G. Wang et al. of Pt/ITO as electrocatalyst for PEFC MEAs revealed strong changes in the indium oxide component after operating conditions. ${ }^{[20]}$ These changes resulted in poor conductivity of the support followed by large activity losses. However, only little work has been done to understand how the entire catalyst/support couple and its components behave directly under AST-conditions with specific emphasis on Pt particle growth and agglomeration as well as support degradation. Deeper understanding of the catalyst during simulated fuel cell operating conditions will be crucial to develop a stable and active material.

In this study, we report new molecular insight in the degradation mechanisms of Pt/ITO electrocatalysts for oxygen reduction at fuel cell cathodes. What sets this study apart from previous ones is the use of a number of different in situ electrochemical X-ray and flow cellinductively coupled plasma (ICP) techniques to track the change in the molecular structure and composition of the catalysts during ORR catalysis. In situ high energy X-ray diffraction (HE-XRD) and anomalous small angle X-ray scattering (ASAXS) were applied to follow the structure and morphology of the Pt and ITO particles. In addition, scanning flow cell tests coupled to inductively coupled plasma mass spectroscopy (SFC ICP-MS), XPS, high angle annular dark field scanning transmission electron microscopy (HAADF STEM) combined with energy-dispersive X-ray (EDX) spectroscopy yielded a deeper understanding of the evolution of morphology and surface composition after the ASTs. Together, our experimental study unravels critical parameters determining structural, morphological, compositional and, thus, electrochemical stability of Pt on ITO. 


\section{WILEY-VCH}

\section{Results}

\subsection{Physicochemical Characterization}

Platinum nanoparticles supported on Indium Tin Oxide have been synthesized using a solvothermal route using oleylamine and oleic acid as surfactants and dibenzylether as the solvent. The support material was introduced in the reaction mixture from the beginning to enable Pt nanoparticle growth directly on the support. Slow heating rates of $1^{\circ} \mathrm{C} / \mathrm{min}$ were applied to obtain monodisperse Pt nanoparticles.

Figure 1 shows the X-ray diffraction (XRD) pattern of Pt on ITO as well as the pure ITO. All reflexes in the ITO pattern can be clearly assigned to an $\mathrm{In}_{2} \mathrm{O}_{3}$ phase (PDF\#00-006-0416). No additional $\mathrm{Sn}$ oxide phase was present indicating complete incorporation of $\mathrm{Sn}$ into the $\mathrm{In}_{2} \mathrm{O}_{3}$ lattice thus, forming $\mathrm{In}_{2-\mathrm{x}} \mathrm{Sn}_{\mathrm{x}} \mathrm{O}_{3}$ crystallites. The Pt/ITO pattern shows broad Pt reflections for pure face-centered cubic (fcc) Pt.

To analyze Pt particle size and Pt particle distribution on the support, transmission electron microscopy (TEM) was applied. Figure 2a,b shows quite homogeneously distributed $\mathrm{Pt}$ nanoparticles on the ITO support with an average size of 5.3 $\pm 0.7 \mathrm{~nm}$ (Figure 2c). Furthermore, the support consists of mostly well faceted nanocrystals with a size $>10 \mathrm{~nm}$. These crystals are randomly oriented and clearly distinguishable from the small $\mathrm{Pt}$ nanoparticles. The composition of the Pt/ITO as determined by inductively coupled plasma optical emission spectroscopy (ICP-OES) revealed a weight loading of $22.0 \mathrm{wt} \% \mathrm{Pt}$ on ITO for the initial state (Figure 2a,b). This sample was used for low potential accelerated stress test (LP-AST) experiments. For all high potential (HP-) AST experiments the sample had a weight loading of $29.9 \mathrm{wt} \% \mathrm{Pt}$ on ITO. Figure S1 shows TEM images and the corresponding histogram of the Pt particle size in the initial state. It can be clearly seen that Pt particle size and distribution as well as the shape and size of the support crystallites was almost identical compared to the sample with lower loading that was used for LP-AST. 


\section{WILEY-VCH}

\subsection{Electrochemical Characterization}

Figure 3a depicts the cyclic voltammograms (CVs) of the Pt/ITO catalyst in the initial state and after $5 \mathrm{k} \mathrm{CV}$ in the lower potential region from $0.6-0.95 \mathrm{~V}$ vs. RHE (denoted as LP-AST). The ASTs were preceded and followed by CVs in the activation regime $(0.05-1.00 \mathrm{~V})$. It can be clearly seen that the CVs changed after the AST as the current in the Pt-O/-OH region (0.6$0.8 \mathrm{~V}$ ) drastically decreased. This suggests a lower number of oxidizable Pt sites on the nanoparticles after LP-AST. In contrast, the charge transferred in the $\mathrm{H}_{\text {upd }}$ region $(0.05-0.4 \mathrm{~V})$ decreased by only $8 \%$ as shown in Figure 4 representing a minor loss in the hydrogen-based electrochemical active surface area (Hupd-ECSA). The corresponding linear sweap voltammograms (LSV) in Figure $3 \mathrm{~b}$ revealed a loss of the Platinum mass-based activity $\left(\mathrm{j}_{\mathrm{m}}\right)$ by $54 \%$ after LP-AST as evaluated at $0.9 \mathrm{~V}$. To quantify the number of oxidizable Pt sites and to investigate their relation to the loss in mass activity, $\mathrm{CO}$ stripping experiments were performed at selected stages of the electrochemical stability test (Figure S3a). Figure 4 shows a comparison of ECSAs determined in the $\mathrm{Hupd}_{\text {und }} \mathrm{CO}$ oxidation region of the $\mathrm{CO}$ stripping experiment. Note that the absolute values of CO-ECSAs as presented in Figure 4 are larger compared to the $\mathrm{H}_{\text {upd }}$ based values due to a stronger adsorption of $\mathrm{CO}$ on $\mathrm{Pt}$ as it is well known from literature for Pt-based systems. ${ }^{[21,22]}$ However, it can be seen that the CO-ECSA decreased in the course of the LP-AST (-29\%) measurement whereas the Hupd-ECSA was rather stable $(-8 \%)$. This also becomes clear as the ratio $\left(\mathrm{CO} / \mathrm{H}_{\text {upd }}\right)$ of both ECSAs decreased as seen by Table $\mathrm{S} 2$.

After stability test in the higher potential range from $1.0-1.5 \mathrm{~V}$ (denoted as HP-AST) the cyclic voltammogram exhibited higher currents in the $\mathrm{H}_{\text {upd }}$ region compared to the initial state

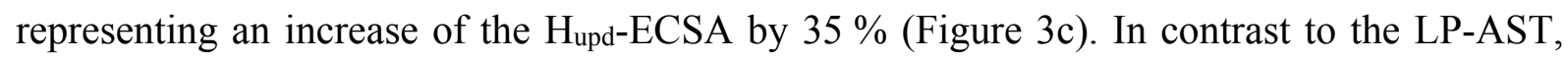
mass-based activity of Pt/ITO decreased by only $15 \%$ (Figure $3 \mathrm{~d}$ ) and the CO-ECSA by only 


\section{WILEY-VCH}

$5 \%$ during the HP-AST (Figure 4). Thus, the catalytic activity of the Pt/ITO is significantly more stable in the HP-AST than in the LP-AST. However, in both cases the catalytic activity followed rather the CO-ECSA than the Hupd-ECSA.

To compare the Pt/ITO electrocatalyst to a commercial carbon supported material, a $20 \mathrm{wt} \%$ $\mathrm{Pt} / \mathrm{C}$ reference catalyst was applied to the same ASTs. Figure S2a,b shows CVs and LSVs before and after the LP-AST. Pt/C exhibited higher stability in the lower potential regime than Pt/ITO with a loss in mass activity of only $14 \%$ (see also Table S1). In contrast to that, carbon supported catalyst showed a decrease of $38 \%$ in ORR mass activity after the HP-AST and an increase in $\mathrm{H}_{\text {upd-ECSA }}$ of $9 \%$ (Figure S2c,d) suggesting a lower electrochemical stability than Pt/ITO in this potential regime.

To explain the changes in electrochemical surface area and catalytic activity towards the oxygen reduction reaction (ORR), the evolution of particle size after the ASTs was analyzed by TEM (Figure $2 \mathrm{~d}-\mathrm{i}$ ). The size of the Pt nanoparticles increased only slightly by around $1 \mathrm{~nm}$ from $5.3 \pm 0.7$ to $6.4 \pm 0.9 \mathrm{~nm}$ after LP-AST (Figure $2 \mathrm{~d}$-e) which could explain the small

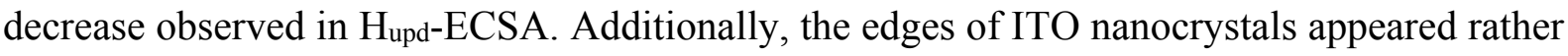
rounded compared to the faceted ITO crystallites of the initial state and the Pt particles seem to be more agglomerated.

After HP-AST (Figure 2g-i), the Pt nanoparticles did not grow as they exhibited an average diameter of $5.2 \pm 0.6 \mathrm{~nm}$. Therefore, the observed increase in Hupd-ECSA cannot be explained by the stable particle size distribution. In contrast to LP-AST, the nanocrystals of the ITO support did not only change in shape after HP-AST but did not appear to be well separated anymore indicating coalescence to larger particles.

\subsection{XPS and STEM/EDX results}




\section{WILEY-VCH}

To get deeper insight into the changes of the Pt surface, X-ray photoelectron spectroscopy (XPS) was performed on the Pt/ITO before and after the LP-AST and Figure S4 shows the $\mathrm{Pt} 4 \mathrm{f}$ as well as the In and Sn $3 \mathrm{~d}$ spectra of Pt/ITO. From the Pt $4 \mathrm{f}$ depth profile it can be seen that Pt in both samples is mostly metallic with a binding energy of around $71.1 \mathrm{eV}$ (Figure $\mathrm{S} 4 \mathrm{a}, \mathrm{b})$. The initial state exhibited also a small fraction of $\mathrm{PtO}_{\mathrm{x}}$ species (contribution at around $72 \mathrm{eV}$ ) which was absent after the LP-AST. This finding is in agreement with the HR-TEM micrographs in Figure $\mathrm{S} 5 \mathrm{c}, \mathrm{d}$ where a sub-nm amorphous shell around of the metallic $\mathrm{Pt}$ nanoparticles is visible in the as-prepared state. This shell can be explained with a thin layer of Pt oxide around the nanoparticles that disappeared upon electrochemical cycling. The ITO was assessed by In and Sn 3d core levels (see Figure S4c,d) and no difference was identified between the two analyzed states.

Table 1 shows the quantitative results from the XP spectra as obtained at two different positions of the sample. On the one hand the $\mathrm{Pt} /(\mathrm{In}+\mathrm{Sn})$ ratio increased slightly indicating support leaching and furthermore, the In/Sn ratio changed towards lower $\mathrm{Sn}$ concentration. To analyze the Pt surface and the elemental distribution in the catalyst in more detail, High-angle annular dark field (HAADF) scanning transmission electron microscopy (STEM) images and energy-dispersive X-ray (EDX) maps were acquired. In Figure 5a,b the STEM-EDX mappings of a Pt nanoparticle deposited on ITO particles are shown before and after the LPAST. Pt can be clearly distinguished from the support and no clear difference between the two states in terms of Pt particle size and elemental distribution is observed. In addition, In and Sn were homogenously distributed in the ITO support and did not change drastically after potential cycling.

\subsection{In situ HE X-ray investigation}

We performed in situ high energy X-ray diffraction (HE-XRD) and anomalous small angle Xray scattering (ASAXS) to track and analyze the structural and morphological evolution of $\mathrm{Pt}$ 


\section{WILEY-VCH}

particles as well as of $\operatorname{In}_{2-\mathrm{x}} \mathrm{Sn}_{\mathrm{x}} \mathrm{O}_{3}$ crystallites during the AST and, thus, to gain deeper understanding about their degradation pathways. Figure S6a shows the evolution of X-ray diffraction patterns during the LP-AST including the initial state. It can be clearly seen that the Pt reflexes did not decrease in intensity whereas the intensity of the $\operatorname{In}_{2-\mathrm{x}} \mathrm{Sn}_{\mathrm{x}} \mathrm{O}_{3}$ reflexes decreased drastically and thus, $\mathrm{Pt} / \mathrm{In}_{2-\mathrm{x}} \mathrm{Sn}_{\mathrm{x}} \mathrm{O}_{3}$ ratio increased. The results of Rietveld Refinement (Figure 6a,b) show that the crystalline fraction of $\operatorname{In}_{2-\mathrm{x}} \mathrm{Sn}_{\mathrm{x}} \mathrm{O}_{3}$ decreased from $79 \%$ to $61 \%$ during the LP-AST. The scale factor of the two crystalline phases (Figure S12a) confirms the constant absolute amount of Pt and the loss of $\mathrm{In}_{2-\mathrm{x}} \mathrm{Sn}_{\mathrm{x}} \mathrm{O}_{3}$ during LP-AST. Simultaneously, the Pt coherence length grew only slightly from the initial value of $4.33 \pm 0.27 \mathrm{~nm}$ to $4.59 \pm 0.27 \mathrm{~nm}$ whereas the $\mathrm{In}_{2-\mathrm{x}} \mathrm{Sn}_{\mathrm{x}} \mathrm{O}_{3}$ coherence length strongly increased from $13.89 \pm 0.29 \mathrm{~nm}$ to $16.19 \pm 0.46 \mathrm{~nm}$. To gain a deeper insight in the evolution of the $\mathrm{Pt}$ nanoparticles, Pt-specific scattering curves were obtained from ASAXS measurements around the Pt K-edge. Figure S7a shows the background-corrected scattering curves with a clear feature visible above $0.1 \AA^{-1}$ resulting from Pt nanoparticles. By fitting these scattering curves and assuming a Gaussian distribution of spheres the particle size distribution (PSD) can be obtained (Figure S7b). We identified a bimodal PSD with a high fraction (ca. 99\%) of Pt particles with a size of around $4.5 \mathrm{~nm}$ and a small fraction (ca. 1\%) of larger particles with a diameter of $9 \mathrm{~nm}$. This finding shows that only a very slight fraction of the Pt particles was agglomerated.

The size of Pt nanoparticles stayed almost constant during the LP-AST but the agglomerated Pt particles shrink by $\sim 1 \mathrm{~nm}$ (Figure 6c). Additionally, we noticed a slight decrease in size of the Pt particles between the as-prepared state and the start of the stability test. Furthermore, we identified that the monodispersity $\sigma$ of the Pt nanoparticles decreased slightly from 0.40 to 0.37. Thus, the results achieved by ASAXS support the findings from Rietveld analysis and show the excellent morphological and structural stability of the Pt nanoparticles which contrasts the evolution of the ITO support. Furthermore, we state that no significant loss in the 


\section{WILEY-VCH}

absolute intensity of the Pt scattering/reflections was obtained although the ITO support dissolved or became amorphous indicating a negligible loss of Pt nanoparticles.

Figure S6b shows the evolution of diffraction patterns during HP-AST and the intensities of the ITO reflexes decreased less strongly than during LP-AST. The evolution of fraction of the crystalline phases as determined by Rietveld Refinement is shown in Figure 7a. It can be seen that the fraction of $\mathrm{In}_{2-\mathrm{x}} \mathrm{Sn}_{\mathrm{x}} \mathrm{O}_{3}$ decreased by around $5 \%$ from $67 \%$ to $62 \%$ whereas the $\mathrm{Pt}$ fraction simultaneously increased by the same extent. From the initial dry state to the state directly before the stability test an initial drop of the $\mathrm{In}_{2-\mathrm{x}} \mathrm{Sn}_{\mathrm{x}} \mathrm{O}_{3}$ fraction of $3 \%$ was observed which can be explained with a partial dissolution (or amorphization) of the $\mathrm{In}_{2-\mathrm{x}} \mathrm{Sn}_{\mathrm{x}} \mathrm{O}_{3}$ during the CVs in the activation regime. During the first $500 \mathrm{CVs}$ of the HP-AST the $\operatorname{In}_{2-\mathrm{x}} \mathrm{Sn}_{\mathrm{x}} \mathrm{O}_{3}$ again fraction increased. The scale factor of the two crystalline phases (Figure S12b) confirms the loss of absolute amount of $\mathrm{Pt}$ and of $\mathrm{In}_{2-\mathrm{x}} \mathrm{Sn}_{\mathrm{x}} \mathrm{O}_{3}$ during HP-AST. Throughout the whole HP-AST, the coherence length of both $\mathrm{Pt}$ and $\mathrm{In}_{2-\mathrm{x}} \mathrm{Sn}_{\mathrm{x}} \mathrm{O}_{3}$ remained constant with a size of $4.25 \pm 0.19 \mathrm{~nm}$ and $12.94 \pm 0.44 \mathrm{~nm}$, respectively (Figure $7 \mathrm{~b}$ ). Complementary to these in situ HE-XRD measurements, the results from ASAXS experiments show the stability of the Pt nanoparticles during the HP-AST as the mean particle size remained constant (Figure 7c) and the monodispersity $\sigma$ increased slightly from 0.41 to 0.43 (Figure S8c).

Generally, we state that perfect agreement between particle, crystallite size and structural coherence length determination by TEM, (A)SAXS and HE-XRD demands very high degree of homogeneity in shape, size and crystallinity which was not given in this study. ${ }^{[26]}$

\subsection{In situ SFC ICP-MS}

To differentiate between amorphization and dissolution/detachment of the ITO support and to track the dissolution of $\mathrm{Pt}$, In and Sn, experiments with an in situ scanning flow cell (SFC) coupled to an inductively coupled plasma mass spectroscopy (ICP-MS) were performed. The LP- and HP-ASTs were applied to the Pt/ITO and to the Pt/C reference catalyst. 


\section{WILEY-VCH}

Figure 8 shows the results from in situ SCF ICP-MS experiments for the two different potential regimes and it can be seen that a large dissolution peak arises for all three metals when the first contact between the electrode and the acidic electrolyte under open circuit potential (OCP) conditions was established (denoted as cell contact). During potential cycling in the activation regime $\mathrm{Pt}$ dissolution was observed in case of the ITO and $\mathrm{C}$ support. The Pt dissolution was up to $0.5 \mu \mathrm{g}_{\operatorname{det}} \mathrm{L}^{-1} \mu \mathrm{g}_{\mathrm{WE}}{ }^{-1}$ but limited to the first potential cycles (see Figure 8a) and no major difference between Pt/ITO and Pt/C was observed. No further Pt dissolution was observed during potential cycling in the activation and the LP regime.

During potential cycling in the activation and in the LP regime a low but constant dissolution of In and Sn was observed (0.05 and $0.1 \mu \mathrm{g}_{\operatorname{det}} \cdot \mathrm{L}^{-1}$, respectively). Thus, the ITO dissolved continuously over the whole course of the applied electrochemical protocol without any specific potential dependence.

In case of the HP regime (Figure $8 \mathrm{~b}$ ) a relatively broad Pt dissolution peak can be observed for both carbon and oxide supports, but again, Pt dissolution was significantly more pronounced for Pt/C than for Pt/ITO. We determined the amount of Pt dissolution during the first cycles in the HP regime to be $1 \cdot 10^{-3} \mu \mathrm{g}_{\operatorname{det}} \cdot \mu \mathrm{g}_{\mathrm{WE}}{ }^{-1}$ for $\mathrm{Pt} / \mathrm{C}$ and $3 \cdot 10^{-4} \mu \mathrm{g}_{\operatorname{det}} \cdot \mu \mathrm{g}_{\mathrm{WE}}{ }^{-1}$ for Pt/ITO (see also Figure S11). Note that Pt dissolution becomes more pronounced during the activation potential cycles after the potential cycling in the HP regime compared to that in the LP regime. A likely explanation is the reductive dissolution of the electrochemically-formed $\mathrm{PtO}_{\mathrm{x}}$ species. ${ }^{[2,23]} \mathrm{Pt}$-specific dissolution behavior with a small oxidative dissolution peak and a big and sharp peak in the reductive scan of the AST were superimposed by a broad and decreasing dissolution signal due to the relatively high scan rate of $500 \mathrm{mV} \mathrm{s}^{-1}$ in the HP-AST. In addition to the dissolution peaks of In and Sn upon first cell contact, a small Sn dissolution peak was observed at the beginning of the activation regime which remained comparable in intensity to $\mathrm{Sn}$ dissolution during the LP-AST. Slight In and a more pronounced Sn dissolution was also detected during the first cycles in the HP regime and, thus, the observed 


\section{WILEY-VCH}

Pt loss was likely caused by Pt nanoparticle detachment due to support dissolution. Data evidences that $\mathrm{Sn}$ is more prone to dissolve during the HP-AST. Generally, we state that only $0.04 \%(0.10 \%)$ of Pt and $1.89 \%(2.47 \%)$ of the ITO support was dissolved over the whole course of the applied though shorter electrochemical protocol for the LP (HP) regime. For comparison, in case of the $\mathrm{Pt} / \mathrm{C}$ reference $0.09 \%(0.29 \%)$ of the total Pt mass was dissolved (see also Table S3). 


\section{WILEY-VCH}

\section{Discussion}

Associated with the need of developing new and stable electrocatalysts for PEM fuel cells, an in situ stability study of ITO-supported Pt nanoparticles has been conducted. We were able to successfully deposit Pt nanoparticles with a uniform size on the highly crystalline support. The catalyst was tested for electrochemical stability under simulated fuel cell conditions by applying two different ASTs representing conventional operating conditions (0.6-0.95 V) and start-up/shut-down (1.0-1.5 V). By employing a wide range of in situ (X-ray) techniques as well as advanced spectroscopy and electron microscopy we aimed to determine fundamental descriptors for electrochemical catalyst and support stability as well as the most prominent degradation pathway.

\section{Electrochemical versus structural stability}

The investigation of electrocatalytic stability in acidic media applying two different protocols has revealed that Pt/ITO shows higher electrochemical stability in the HP-AST than in the LP-AST. In particular, ORR activity and CO-ECSA decreased strongly during the LP-AST

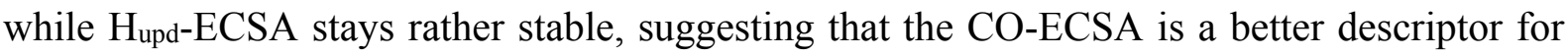
the ORR active site density. These findings show that the Pt surface after LP-AST remains accessible for $\mathrm{H}$ adsorbates represented by a stable $\mathrm{Hupd}$-ECSA but not for $\mathrm{O} / \mathrm{OH}$ adsorbates which are essential for the oxygen reduction reaction. TEM analysis shows almost no growth of Pt nanoparticles and a slightly higher degree of Pt agglomeration. This slightly higher degree of agglomeration of the Pt particles can explain the small decrease of the accessible surface area as measured via $\mathrm{H}_{\text {upd }}$ but the CO-ECSA decreased to a higher extent. In situ Xray investigations again proofed that $\mathrm{Pt}$ particle and crystallite size was stable over the LP-AST and in situ SFC ICP-MS showed negligible Pt dissolution. The morphological and structural stability of the Pt nanoparticles contrasts the strong loss in catalytic activity. 


\section{WILEY-VCH}

Thus, the major changes in ITO indicate a strong influence of the morphological stability of ITO on the catalytic activity of Pt. In situ X-ray investigations revealed that the fraction of crystalline ITO strongly decreased and the crystallite size increased. Hence, the ITO is partially dissolved/detached or loses crystallinity during LP-AST. From in situ SFC ICP-MS measurements a small but continuous dissolution of In and Sn was observed, but the observed loss from HE-XRD in ITO weight fraction is much higher suggesting partial amorphization of ITO. Dissolved In/Sn ions are prone to be (electro)chemically- and isostructurally-redeposited on the ITO crystallites which can explain the determined growth via Ostwald ripening. ${ }^{[24]}$ Alternatively, the loss of smaller crystallites would lead to a larger mean crystallite size.

We have to note that the loss of crystalline ITO is not directly linked to a loss of Pt nanoparticles. Rietveld Refinement shows that the absolute amount of Pt remained stable during the LP-AST whereas the absolute amount of crystalline ITO strongly decreased (as measured by the scale factor extracted from fits of the HE-XRD pattern, see Figure S12a). These findings suggest that ITO gets preferentially dissolved where locally no Pt is present and that the Pt nanoparticles might be stabilizers of ITO. By acting as electron scavenger the Pt avoids the electrochemical reduction of the surface $\mathrm{In} / \mathrm{Sn}$ ions and thus, reduces their dissolution into the electrolyte This function is similar to the role of an appropriate cocatalysts on photoanodes acting as hole scavengers leading to enhanced photoelectrocatalytic stability. ${ }^{[25]}$ Thus, we can conclude that while Pt is almost unaffected by the conditions present during LP-AST, the tremendous changes of the ITO influence the stability of the electrocatalytic activity of the Pt nanoparticles.

The AST in the HP regime from 1.0-1.5 V revealed a significantly better stability of the catalytic activity. TEM analysis and in situ X-ray results showed that ITO nanocrystals and Pt nanoparticles did not grow and the composition remained stable compared to the LP-AST. This agrees with a rather stable CO-ECSA and hence with a stable mass-based activity, which again shows the dependency of these two descriptors. In contrast, the Pt surface area became 


\section{WILEY-VCH}

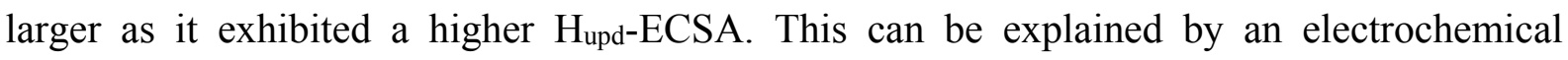
roughening of the Pt surface as elevated Pt dissolution was observed from in situ SCF ICPMS during the HP-AST. Furthermore, the dissolved Pt ions could be redeposited on the cathode as sub-nm clusters or single atom sites which we did not detect by electron microscopy and HE-XRD. But these domains would contribute to the increase in the $\mathrm{H}_{\text {upd- }}$ ECSA and would lower the dissolution rate with respect to the loss of crystalline $\mathrm{Pt}$ nanoparticles. The Pt dissolution during HP-AST was accompanied by small In and more pronounced Sn dissolution affecting the shape of the ITO crystallites as observed in TEM images. However, these changes influenced the structure and morphology of the ITO less strongly than during the LP-AST and without a tremendous impact on the catalytic performance. Additionally, the loss of crystalline $\operatorname{In}_{2-\mathrm{x}} \mathrm{Sn}_{\mathrm{x}} \mathrm{O}_{3}$ from in situ HE-XRD could rather be assigned to support leaching than to amorphization as concluded for LP-AST.

The comparison of the electrochemical results revealed a higher stability for the $\mathrm{Pt} / \mathrm{C}$ reference in the LP-AST when compared to the Pt/ITO catalyst. Dissolution of $\mathrm{Pt}$ in $\mathrm{Pt} / \mathrm{C}$ during the LP-AST was very low and comparable to that of Pt/ITO, indicating similar morphological Pt stability in Pt/C and Pt/ITO. After HP-AST the reference material revealed a lower stability with a relatively big loss in catalytic activity. From in situ ICP-MS it can be seen that during cycling in the range of 1.0-1.5 V Pt dissolution was much more pronounced in $\mathrm{Pt} / \mathrm{C}$ than in $\mathrm{Pt} / \mathrm{ITO}$. This can be explained with a stronger electronic interaction between the metal particles and the oxide support impeding nanoparticle detachment or dissolution but could also be caused by the differences in particle size and, thus, electrochemical surface area. In that respect, initial $\mathrm{Pt}$ dissolution peaks at cell contact due to $\mathrm{PtO}_{\mathrm{x}}$ reduction at $\mathrm{OCP}$ conditions were again smaller for ITO supported $\mathrm{Pt}$. ITO might decrease $\mathrm{PtO}_{\mathrm{x}}$ formation resulting in lower peak intensity compared to the $\mathrm{Pt} / \mathrm{C}$ reference.

\section{Catalyst/support degradation pathways}




\section{WILEY-VCH}

From the above described electrochemical and structural behavior of Pt/ITO under operating conditions we conclude that the support stability has a tremendous impact on the stability of the catalytically active sites. We are able to exclude well-known catalyst degradation phenomena caused by Pt particle growth, agglomeration and dissolution/detachment and propose a pathway based on strong influence of support degradation on the availability of $\mathrm{Pt}$ active sites. In detail, we found an overall excellent structural and morphological stability of Pt but we determined altering of the ITO support as a likely actuator for Pt (surface) poisoning and resulting performance loss in the ASTs, especially in the LP-AST.

For the LP-AST, XPS data indicate support loss in the form of Sn leaching and continuous but small support dissolution was also found by in situ ICP-MS. The dissolved metal ions could be electrochemically redeposited not only preferentially on the ITO surface but also on the Pt surface during the relative reductive conditions of cycling between $0.6-0.95 \mathrm{~V}$. The increasing $\mathrm{Pt} /(\mathrm{In}+\mathrm{Sn})$ ratio from XPS after LP-AST is dominated by the preferential dissolution (or detachment) of the support but does not exclude Pt surface modification.

Consequently, we aim to uncover the origin for this poisoning effect in the form of proposed degradation pathways. Possible mechanisms for Pt surface poisoning could be (a) support metal incorporation into Pt nanoparticles leading to alloy formation, (b) formation of an amorphous metal (oxyhydr)oxide layer or (c) redeposition of In and/or $\mathrm{Sn}$ ions on the $\mathrm{Pt}$ surface.

Metal diffusion into Pt leading to alloy formation preferentially due to Sn alloying into the $\mathrm{Pt}$ lattice could also lower catalytic activity. In that respect, no other phase was observed during potential cycling in the HE-XRD, but the evolution of Pt lattice constant from Rietveld Refinement during the LP-AST was tracked as PtSn alloy formation should increase the lattice constant (PtSn3, PDF\#00-035-1360). Figure S13a shows such evolution over the cycle number in the LP-AST. Here, it can be seen that the lattice constant decreases from beginning to end of cycling. Furthermore, the formation of a near-surface alloy leading to a PtSn shell is 


\section{WILEY-VCH}

unlikely because this would lead to a decrease of the Pt coherence length. Thus, PtSn alloy formation is unlikely and can therefore be excluded for the major Pt poisoning contributors.

Another interpretation of the combination of electrochemical and in situ results can be the partial transformation of ITO to an amorphous $\mathrm{In} / \mathrm{SnO}_{\mathrm{x}}(\mathrm{OH})_{\mathrm{y}}$. This (oxyhydr)oxide formation could then lead to a (partial) encapsulation in the form of a thin (mono)layer around Pt. This theory would go in line with relatively strong loss of crystalline $\mathrm{In}_{2-\mathrm{x}} \mathrm{Sn}_{\mathrm{x}} \mathrm{O}_{3}$ fraction from HEXRD and only little In and Sn dissolution from ICP-MS. This layer would be permeable for protons but not for larger molecules like $\mathrm{CO}$ or $\mathrm{OH}$ and can thus, explain the different trends in Hupd- and CO-ECSA. This phenomenon, also known as "decoration effect", originates from SMSI and is well known in literature for different metals ( $\mathrm{Rh}, \mathrm{Pt}, \mathrm{Pd}, \mathrm{Ni}, \mathrm{Co})$ supported on metal oxides $\left(\mathrm{TiO}_{2}, \mathrm{Fe}_{3} \mathrm{O}_{4}, \mathrm{WO}_{\mathrm{x}}\right) .{ }^{[27]}$ In these studies, the encapsulation has been induced by thermal/chemical reduction of the oxide support as well as electrochemical reduction at low potentials in the case of $\mathrm{Pt} / \mathrm{WO}_{\mathrm{x}}$. In our case, the LP-AST in acidic electrolyte implies reductive reaction conditions for the oxide support. In photocatalysis this effect is intentionally induced to suppress ORR in hydrogen evolution catalysts by growing a protonand hydrogen-permeable $\mathrm{Cr}_{2} \mathrm{O}_{3}$ shell around an $\mathrm{Rh}$ catalyst. This shell is impermeable for $\mathrm{O}_{2}$ molecules inhibiting undesired ORR. ${ }^{[28]}$ We identified a marginal growth of Pt particles by less than $1 \mathrm{~nm}$ in TEM micrographs after LP-AST (Figure 2) while the coherence length/domain size (as obtained by HE-XRD) and particle size (as obtained by ASAXS) remained constant. This finding would go in line with the formation of sub-nm (oxyhydr)oxide layer around Pt but can also be within the error of particle size estimation from TEM due to higher degree of agglomeration. However, we could not proof the formation of this layer by STEM images and EDX spectroscopy but a sub-monolayer coverage or adsorption might be hard to detect even though it is present and might also be superimposed by other phenomena such as particle agglomeration. Also XP spectroscopy does not give the sensitivity to differentiate between the chemically-unchanged because isostructurally-grown 


\section{WILEY-VCH}

$\mathrm{In}_{2-\mathrm{x}} \mathrm{Sn}_{\mathrm{x}} \mathrm{O}_{3}$ crystallites and sub-monolayer coverage of the support metal ions on the surface of the Pt nanoparticles. However, we expect the ad-atoms to differ chemically from the $\mathrm{Sn} / \mathrm{In}$ ions in the $\operatorname{In}_{2-\mathrm{x}} \mathrm{Sn}_{\mathrm{x}} \mathrm{O}_{3}$.

It is known from literature that In and/or Sn metal adsorbates present as sub-monolayer on $\mathrm{Pt}$ single crystal surfaces with Sn strongly affects the CO oxidation behavior. ${ }^{[29]}$ Therein, adsorbed Sn on various Pt surfaces lead to a growth of the oxidation peak at $0.53 \mathrm{~V}$. In case of the Pt (111) surface Sn coverage blocks the more anodic $\mathrm{CO}$ oxidation peak at $0.65 \mathrm{~V}$ whereas it does not affect the CO electrooxidation on $\mathrm{Pt}(100)$ and (110) surface. CO electrooxidation on the Pt/ITO catalyst also shows a preferential poisoning of the high potential oxidation peak after the LP-AST and thus, our electrochemical data are in agreement with the surface poisoning of the Pt nanoparticles with metal (Sn) ions (Figure S3). We note that the anodic shift of the $\mathrm{CO}$ oxidation potential might be caused by the In adsorbates in addition to $\mathrm{Sn}$. In another approach, $\mathrm{Pt}$ supported on $\mathrm{Nb}$ - and $\mathrm{Sb}$-doped $\mathrm{SnO}_{2}$ was used as catalyst for single cell stability tests and it was found that Sn was dissolved at reducing potentials resulting in $\mathrm{Pt}$ poisoning by $\mathrm{Sn}$ redeposition. ${ }^{[30]}$ Nakada et al. reported on $\mathrm{SnO}_{2}$ supported Pt electrocatalyst and they found decreased Pt oxidation/reduction current due to stronger interactions of $\mathrm{Sn}$ with $\mathrm{Pt}$ after electrochemical cycling. ${ }^{[31]}$ Additionally, under potential deposited (UPD) Sn on Pt was found to change the Pt oxidation behavior when cycling in $\mathrm{HClO}_{4}{ }^{[32]}$

In case of the HP-AST the dominant degradation mechanism is $\mathrm{Pt}$ dissolution from $\mathrm{PtO}_{\mathrm{x}}$ species by reaching potentials high as $1.5 \mathrm{~V}$. Interestingly, ITO support dissolved as well in this potential regime leading to support modification, but did not affect the electrochemical performance drastically. We explain that with the slight but continuous dissolution of surface Pt atoms under oxidative conditions which continuously pours away potentially adsorbed $\mathrm{In} / \mathrm{Sn}$ atoms. This process prevents significant poisoning with $\mathrm{In} / \mathrm{Sn}$ atoms and, thus, leads to a rather stable mass-based catalytic activity. Furthermore, cathodic potentials as low as $0.6 \mathrm{~V}$ 


\section{WILEY-VCH}

as in LP-AST might be required to form metal (oxyhydr)oxides or Sn UPD layer on the Pt surface.

For the HP-AST regime we clearly established a superior structural stability of $\mathrm{Pt}$ nanoparticles on ITO versus C supports. Some earlier work put forward strong electronic interactions between metal particles and the oxide support impeding nanoparticle detachment. ${ }^{[13,33]}$ Recent DFT calculations showed that the electronic influence of oxide support is limited to the few atom layers of $\mathrm{Pt}^{[34]}$ The Pt nanoparticles in this work are significantly larger and, thus, electronic interactions may remain masked from spectroscopic identification although they are indeed anchored more strongly to oxide supports.

Combining all these results, we propose that the activity loss during the LP-AST is caused by a kind of Pt surface modification due to In and, more likely, Sn accumulation. During HPAST this degradation pathway is blocked because slight anodic dissolution of Pt keeps the active sites accessible. 


\section{WILEY-VCH}

\section{Conclusion}

We have explored the stability and degradation of Pt nanoparticles supported on ITO support during the electrocatalytic reduction of molecular oxygen as well as during two distinct degradation regimes corresponding to normal fuel cell operation and a start-up shut-down operation, respectively. The Pt/ITO electrocatalyst consisted of monodisperse, welldistributed Pt particles with a size of around $5 \mathrm{~nm}$ and was investigated using a number of different in situ techniques i) to gain fundamental insight in the degradation mechanisms ii) to unravel fundamental descriptors of structural and morphological stability iii) to determine stability limitations of this material system. Our combination of X-ray and electron microscopic techniques has advanced our understanding of the fundamental processes associated with the degradation behavior of Pt/ITO electrocatalysts.

Under catalytic ORR operation conditions (LP-AST) we have demonstrated that Pt nanoparticles remain morphologically stable and degradation pathways due to Pt instability can be excluded, whereas the ITO support suffers from cathodic corrosion co-affecting the catalytic stability and mechanical/chemical attachment of the $\mathrm{Pt}$ nanoparticles. ITO crystallites partially dissolve, become amorphous and grow via an Ostwald ripening mechanism. Therefore, we have strong indications that the significantly declined catalytic ORR activity after LP-AST is attributed to partial $\mathrm{In} / \mathrm{Sn}$ redeposition and concomitant surface decoration of active Pt particle. Such oxidic Pt surface adlayers change the Pt redox chemistry and lower the density of specific O-adsorption sites. An encapsulation of the Pt nanoparticles with an (oxyhydr)oxide layer could equally account for this behavior, yet was not fully supported by the available data. In contrast, during start-up/shut-down cycles (HP-AST), the catalyst/support couple showed excellent stability, thanks to the improved structural and morphological durability of the oxide support compared to the commercial $\mathrm{Pt} / \mathrm{C}$ couple. We 


\section{WILEY-VCH}

found evidence for slight continuous anodic Pt dissolution which aided in suppressing $\mathrm{Pt}$ surface poisoning and thus stabilizing the available active site density.

Overall, this study has unraveled the major degradation pathways of ITO-supported Pt nanoparticle fuel cell catalysts over wide cathode potential ranges; our findings advance our understanding of the fundamental aspects of support stability. They are also of practical value for the development of improved fuel cell devices, as they offer design criteria and performance limitations of oxide-based PEFC cathode catalysts. 


\section{WILEY-VCH}

\section{Experimental Section}

\subsection{Synthesis of ITO}

$\mathrm{In}(\mathrm{Cl})_{3}(1.434 \mathrm{~g}$, Strem Chemicals) was dissolved in deionized (DI) water $(2.16 \mathrm{~mL})$ and the solution was stirred for $10 \mathrm{~min}$. Then $\mathrm{SnCl}_{4}(79.2 \mu \mathrm{L}$, Acros Organics) was added to the solution under stirring for $10 \mathrm{~min}$ followed by addition of ethanol ( $9 \mathrm{~mL}, 200$ proof). Afterwards propylene epoxide (5.5 mL, Sigma Aldrich) was added drop-by-drop to the alcoholic solution at room temperature under continuous stirring for $15 \mathrm{~min}$. When the solution turns milky, stirring was continued for another $10 \mathrm{sec}$ and put into an ice bath afterwards for $10 \mathrm{~min}$. The resulting gel was aged for 10 hours and then subjected to a series of solvent exchange in acetone (Fischer Scientific) for 10 times in 3 days. The acetone-loaded gels were then introduced into a supercritical dryer (SFT-100, Supercritical Fluid Technologies, Inc.), and the acetone was removed using supercritical $\mathrm{CO}_{2}$ extraction $\left(45^{\circ} \mathrm{C}\right.$ and 275.8 bar). The dry gel was further calcined at $820{ }^{\circ} \mathrm{C}$ for 150 minutes in air.

\subsection{Synthesis of Pt nanoparticles on ITO}

Platinum nanoparticles were synthesized using a solvothermal synthesis route based on previous work. ${ }^{[35]}$ In detail, Pt(acac)2 $(0.6 \mathrm{mmol}$, Alfa-Aesar, Pt 48\% min), 1,2-tetradecanediol (1.2 mmol, $90 \%$, Sigma Aldrich), oleylamine (300 $\mu \mathrm{L}, \geq 98 \%$, Aldrich), oleic acid (300 $\mu \mathrm{L}$, $90 \%$, Alfa Aesar) and $100 \mathrm{mg}$ ITO were dispersed in dibenzylether (50 mL, $98 \%$, Fluka). The mixture was stirred under Nitrogen atmosphere to remove excess of oxygen. Then, the temperature was raised to $80{ }^{\circ} \mathrm{C}$ and held for 5 min to ensure complete dissolution of the $\mathrm{Pt}$ precursor and the reducing agent. Afterwards the temperature was raised with the ramping of $1{ }^{\circ} \mathrm{C} / \mathrm{min}$ to $165^{\circ} \mathrm{C}$ and kept for $1 \mathrm{~h}$. The mixture was cooled down to room temperature and ethanol (80 mL, $100 \%$, VWR Chemicals) was added, followed by sonication with an ultrasonic horn for $1 \mathrm{~h}$ and stirring overnight. The supernatant was removed by centrifugation 


\section{WILEY-VCH}

(7800 rpm, $15 \mathrm{~min})$ and washed with ethanol $(40 \mathrm{~mL})$ three times. The received catalyst was freeze dried overnight.

\section{3. $\quad \mathrm{X}$-ray diffraction (XRD)}

Lab-based X-ray diffraction patterns were measured on a Bruker D8 Advance diffractometer in Bragg Brentano geometry using $\mathrm{Cu} \mathrm{K}_{\alpha}$ radiation with a wavelength of $0.154 \mathrm{~nm}$ between 20 and $90^{\circ}$ using a step size of $0.04^{\circ}$ and $7 \mathrm{~s}$ time at each step.

\subsection{Inductively Coupled Plasma Optical Emission Spectroscopy (ICP-OES)}

Compositional analysis was performed using an inductively coupled plasma analysis system (Varian 715-ES). The concentration of the standards was 1,5 and $10 \mathrm{mg} / \mathrm{L}$ and the wavelengths for the Pt measurement were 203.646, 204.939, 212.863, 214.424, 217.468, $224.552 \mathrm{~nm}$.

\subsection{Transmission Electron Microscopy (TEM)}

TEM micrographs were recorded on a FEI Tecnai $\mathrm{G}^{2} 20$ S-TWIN with a $\mathrm{LaB}_{6}$ cathode operating with $200 \mathrm{kV}$ acceleration voltage and a resolution limit of $0.24 \mathrm{~nm}$. Samples were dispersed in ethanol with an ultrasonic horn, drop casted on a $\mathrm{Cu}$ grid and dried in air at $60{ }^{\circ} \mathrm{C}$ for $7 \mathrm{~min}$.

High resolution TEM (HRTEM) was performed using a FEI Titan 80-300 TEM electron microscope with a $\mathrm{C}_{\mathrm{s}}$ corrector for the objective lens (CEOS $\left.\mathrm{GmbH}\right)$. The microscope was operated at $300 \mathrm{kV} \cdot{ }^{[36]}$

5.6. High-angle annular dark field (HAADF) scanning transmission electron microscopy (STEM) and energy-dispersive X-ray (EDX) spectroscopy 


\section{WILEY-VCH}

STEM was performed using a FEI Titan G2 80-200 (“ChemiSTEM”) electron microscope

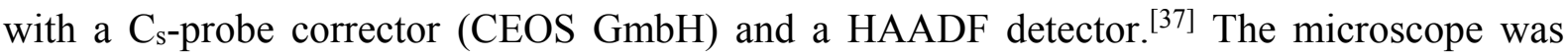
operated at $200 \mathrm{kV}$. In order to achieve "Z-Contrast" conditions, a probe semi-angle of $25 \mathrm{mrad}$ and an inner collection semi-angle of the detector of $88 \mathrm{mrad}$ were used. Compositional maps were obtained with EDX using four large-solid-angle symmetrical Si drift detectors. For EDX elemental mapping, Pt L, Sn L and In L peaks were used.

\subsection{Electrochemical Characterization}

Catalyst Ink preparation: Catalyst powder $(6 \mathrm{mg})$ was added to water $(1.99 \mathrm{~mL}),{ }^{\mathrm{i}} \mathrm{PrOH}$ (500 $\mu \mathrm{L}, \geq 99.95 \%$, Sigma Aldrich) and Nafion solution (10 $\mu \mathrm{L}, 5 \mathrm{wt} \%$, Sigma Aldrich) and sonicated using an ultrasonic horn for $30 \mathrm{~min} .10 \mu \mathrm{L}$ of the ink was drop casted on a $5 \mathrm{~mm}$ diameter glassy carbon (GC) electrode and dried in air at $60{ }^{\circ} \mathrm{C}$ for $7 \mathrm{~min}$. The $\mathrm{GC}$ electrodes were pretreated by polishing in two steps using Buehler alumina polishing solution with diameter 1.0 and $0.05 \mu \mathrm{m}$. A geometric Pt loading of around $25 \mu \mathrm{g}_{\mathrm{Pt}} \mathrm{cm}^{-2}$ was obtained.

Rotating Disc Electrode (RDE): A commercial three electrode cell was used for electrochemical characterization consisting of a Pt mesh (furled $\mathrm{Pt} 5 \times 5 \mathrm{~cm}^{2}$ ) as counter electrode and a mercury/mercury sulfate (MMS) reference electrode $\left(\mathrm{Hg} / \mathrm{Hg}_{2} \mathrm{SO}_{4}\right.$, Ametek, potential $-0.722 \mathrm{~V}$ vs reversible hydrogen electrode (RHE)). $0.1 \mathrm{M} \mathrm{HClO}_{4}$ (diluted with MiliQ from $70 \% \mathrm{HClO}_{4}, 99.999 \%$ trace metal bases, Sigma Aldrich) was used as electrolyte for all electrochemical measurements. A SP-150 or SP-200 Potentiostat (BioLogic Instruments) was used to control the potential of the working electrode and a commercial AFMSRCE rotator (Pine Research) to control rotation. The degree of purity for the used gases was $99.998 \%$ for oxygen, $99.999 \%$ for nitrogen, $99.999 \%$ for hydrogen and $99.997 \%$ for CO. All potentials are referred to the RHE. 


\section{WILEY-VCH}

Cyclic voltammetry $(\mathrm{CV})$ : CVs were recorded between 0.05 and $1 \mathrm{~V}$ with a scan rate of $100 \mathrm{mV} \mathrm{s}^{-1}$ for 100 cycles under nitrogen atmosphere.

Linear sweep voltammetry (LSV): LSVs were recorded 0.05 and $1 \mathrm{~V}$ with a scan rate of $5 \mathrm{mV}$ $\mathrm{s}^{-1}$ and a rotation speed of $1600 \mathrm{rpm}$ under oxygen atmosphere. Determination of the kinetic currents was done by applying the following equation 1:

$$
\frac{1}{j}=\frac{1}{j_{k}}+\frac{1}{j_{d}}
$$

Here, $\mathrm{j}$ is the current at $0.9 \mathrm{~V}$ whereas $\mathrm{j}_{\mathrm{d}}$ was determined by averaging the diffusion limited current between $0.1-0.6 \mathrm{~V}$ and $\mathrm{j}_{\mathrm{k}}$ is the calculated current density (mass and geometric based). CO stripping: First, the electrolyte is saturated by bubbling with nitrogen for $15 \mathrm{~min}$. Afterwards the working electrode is immersed into the electrolyte at $0.05 \mathrm{~V}$ and $400 \mathrm{rpm}$ and the gas is switched to $\mathrm{CO}$. $\mathrm{CO}$ is then bubbled through the electrolyte for $15 \mathrm{~min}$ to ensure complete coverage of the Pt surface with $\mathrm{CO}$. Afterwards nitrogen is bubbled for another 15 min to remove excess $\mathrm{CO}$ from the electrolyte. $\mathrm{CO}$ stripping is performed by cycling between $0.05-1 \mathrm{~V}$ for 5 cycles with a scan rate of $50 \mathrm{mV} \mathrm{s}^{-1}$. ECSA determination based on the area of the $\mathrm{CO}$ oxidation peak and Hydrogen under potential deposition $\left(\mathrm{H}_{\text {upd }}\right)$ was done by subtracting the first two consecutive cycles of the stripping protocol and integration of the charge between the two cycles. ${ }^{[22]}$ The measured Qco or $\mathrm{QH}_{\mathrm{H}}$ value were normalized with respect to the theoretical value for a two electron transfer $\mathrm{QCO}^{\text {theo }}=420 \mu \mathrm{C} \mathrm{cm}^{-2}$ in case of CO as probe molecule and to the theoretical value for a one electron transfer $\mathrm{QH}^{\text {theo }}=210 \mu \mathrm{C} \mathrm{cm}^{-2}$ in case of desorption of hydrogen.

Stability test: Stability measurements in the lower potential (LP) regime have been performed between $0.6-0.95 \mathrm{~V}$ for $5 \mathrm{k}$ cycles with a scan rate of $100 \mathrm{mV} \mathrm{s}^{-1}$ under nitrogen atmosphere and with the $22.0 \mathrm{wt} \% \mathrm{Pt} / \mathrm{ITO}$ sample. Stability measurements in the high potential (HP) regime have been performed between $1.0-1.5 \mathrm{~V}$ for $5 \mathrm{k}$ cycles with a scan rate of $500 \mathrm{mV} \mathrm{s}^{-1}$ under nitrogen atmosphere and with the $29.9 \mathrm{wt} \% \mathrm{Pt} / \mathrm{ITO}$ sample. Before and after these 


\section{WILEY-VCH}

protocols three CVs between $0.05-1 \mathrm{~V}$ with a scan rate of $100 \mathrm{mV} \mathrm{s}^{-1}$ were performed. Parameters for both stability tests (potential range, scan rate, etc.) were adapted from the US Department of Energy (DoE) fuel cell targets from the year 2016.

A $20 \mathrm{wt} \% \mathrm{Pt} / \mathrm{C}$ catalyst (Pt on Vulcan Carbon, BASF) has been used as reference material for RDE stability measurements.

All presented electrode potentials are iR-corrected by the high frequency resistance $\mathrm{R}_{H F}$ determined by potentiostatic electrochemical impedance spectroscopy at $0.5 \mathrm{~V}$. All measurements have been repeated at least three times in order to ensure reproducibility.

\subsection{In situ high energy X-ray diffraction (HE-XRD) and anomalous small angle X-ray scattering (ASAXS)}

In situ XRD and ASAXS measurements were performed at beamline ID 31 at the European Synchrotron Radiation Facility (ESRF) in Grenoble. Diffraction patterns were recorded using a monochromized X-ray beam $(77 \mathrm{keV})$ focused to $200 \mathrm{x} 6 \mu \mathrm{m}$ using a large area Pilatus $3 \mathrm{X}$ CdTe 2M detector. A transmission cell with a three electrode setup was used for the in situ measurements. ${ }^{[3]}$

For the working electrode a carbon paper sheet was covered 10 times with $10 \mu \mathrm{L}$ of ink dispersion and consecutive drying in air at $60{ }^{\circ} \mathrm{C}$ for $8 \mathrm{~min}$. A Pt wire acted as counter electrode and a $3 \mathrm{M} \mathrm{Ag} / \mathrm{AgCl}$ reference electrode (freshly calibrated against $\mathrm{Pt} / \mathrm{H}_{2}$ electrode) were used. Electrochemical protocols were applied using a SP-200 Potenstiotat (BioLogic Instruments). Diffraction patterns were corrected by the background. The working distance was calibrated using a $\mathrm{CeO}_{2}$ standard (NIST SRM 674b) and $\mathrm{Ag}$ Behenate for SAXS.

ASAXS curves were obtained by subtracting the background-corrected and transmittancenormalized scattering curves recorded at 77 and $77.8 \mathrm{keV}$. The energy of the beamline was aligned using the Pt K-edge absorption spectrum. Fitting of the ASAXS scattering curves was 


\section{WILEY-VCH}

performed using the software package SASfit assuming Gaussian size distribution of spherical particles and a form factor representing a hard sphere was taken into account.

\subsection{X-ray photoelectron spectroscopy (XPS)}

X-ray photoelectron spectroscopy measurements were performed at the ISISS beamline of BESSY II facility operated by Helmholtz Zentrum Berlin. The catalyst ink was drop casted onto a $5 \mathrm{~mm}$ diameter glassy carbon disc and dried for $7 \mathrm{~min}$ at $60{ }^{\circ} \mathrm{C}$. The catalyst was treated by the electrochemical protocol described above including the stability test in the low potential regime. XPS measurements were conducted in ultra-high vacuum (UHV) at room temperature. Pt $4 \mathrm{f}$ depth profiling was accessed by using kinetic energy of the photoelectrons of 210,550 and $1200 \mathrm{eV}$.

\subsection{In situ scanning flow cell (SFC) inductively coupled plasma mass spectroscopy (ICP-MS)}

Catalyst inks of Pt/C and Pt/ITO were prepared with a solution of $5 \%$ Nafion $(25 \mu \mathrm{L}$, SigmaAldrich) and ultrapure water (4.975 mL, 18.2 M , PureLab Plus System, Elga), with an appropriate amount of catalyst powder in order to obtain a final loading of approximately 1.6 $\mu \mathrm{gPt}_{\mathrm{Pt}} \mathrm{cm}^{-2}$. A glassy carbon sheet (SIGRADUR® $\mathrm{G}, \mathrm{HTW}$ ) was polished with $1 \mu \mathrm{m} \mathrm{Al}_{2} \mathrm{O}_{3}$ suspension and extensively rinsed with ultrapure water. The ink was sonicated and subsequently $0.3 \mu \mathrm{L}$ drops were pipetted onto the glassy carbon sheet. The formed spots on the glassy carbon sheet of ca. $0.01 \mathrm{~cm}^{2}$ were used as working electrodes.

Electrochemical and dissolution ( $\mathrm{Pt}, \mathrm{In}$ and $\mathrm{Sn}$ ) measurements were carried out using the previously described SFC ICP-MS (NexION 300X, Perkin Elmer) setup. ${ }^{[38]}$ The cell contact area was $0.035 \mathrm{~cm}^{2}$. A saturated $\mathrm{Ag} / \mathrm{AgCl}$ and graphite rod were used as reference and counter electrode, respectively. Potentials are reported against RHE, which was measured 


\section{WILEY-VCH}

daily prior to experiments. Measurements were carried out in a flow of $0.1 \mathrm{M} \mathrm{HClO}_{4}$ prepared from ultrapure water and Suprapur 70\% perchloric acid (Merck), with continuous argon purging. The flow rate of the SFC ICP-MS was approximately $170 \mu \mathrm{L} \cdot \mathrm{min}^{-1}$, while $10 \mu \mathrm{g} \cdot \mathrm{L}^{-1}$

${ }^{187} \mathrm{Re}$ for Pt and $20 \mu \mathrm{g} \cdot \mathrm{L}^{-1}{ }^{103} \mathrm{Rh}$ for In and Sn were used as internal standards. The dissolution in $\mu \mathrm{g} \cdot \mu_{\mathrm{gt}^{-1}}$ was determined via integration of the ICP-MS signal data by the flow rate (normalized to Pt mass loading on the GC electrode). The integration boundaries were taken from a constant signal area before and after the peak.

\section{Supporting Information}

Supporting Information is available from the Wiley Online Library or from the author.

\section{Acknowledgements}

This project received financial support from German Research Foundation (DFG) through grant STR 596/4-1 ("Pt-Stability”) and the German Federal Ministry of Education and Research (BMBF) through grant 03SF0531B ("HT-linked"). M.H. and M.G. thank the DFG for financial support within the grant HE 7192/1-1. We thank ESRF for allocation of synchrotron radiation beamtime and E. Hornberger and F. Dionigi for their help during beamtimes. ZELMI of Technical University Berlin is acknowledged for their support with TEM measurements. We thank A. Wittebrock for her help with electrochemical measurements. 


\section{WILEY-VCH}

\section{References}

[1] J. Speder; I. Spanos; A. Zana; J. J. K. Kirkensgaard; K. Mortensen; L. Altmann; M. Bäumer,M. Arenz, Surface Science 2015, 631, 278; G. P. Keeley; S. Cherevko,K. J. J. Mayrhofer, ChemElectroChem 2016, 3, 51; C. Baldizzone; L. Gan; N. Hodnik; G. P. Keeley; A. Kostka; M. Heggen; P. Strasser,K. J. J. Mayrhofer, ACS Catalysis 2015, 5, 5000; H. Yano; M. Watanabe; A. Iiyama,H. Uchida, Nano Energy 2016.

[2] S. Cherevko; G. P. Keeley; S. Geiger; A. R. Zeradjanin; N. Hodnik; N. Kulyk,K. J. J. Mayrhofer, Chemelectrochem 2015, 2, 1471.

[3] X. Tuaev; S. Rudi; V. Petkov; A. Hoell,P. Strasser, Acs Nano 2013, 7, 5666.

[4] C. A. Rice; P. Urchaga; A. O. Pistono; B. W. McFerrin; B. T. McComb,J. Hu, Journal of The Electrochemical Society 2015, 162, F1175; F. Hasche; M. Oezaslan,P. Strasser, Journal of the Electrochemical Society 2012, 159, B25; F. Hasche; M. Oezaslan,P. Strasser, Physical Chemistry Chemical Physics 2010, 12, 15251; A. Riese; D. Banham; S. Ye,X. Sun, Journal of the Electrochemical Society 2015, 162, F783; J. Speder; A. Zana; I. Spanos; J. J. K. Kirkensgaard; K. Mortensen; M. Hanzlik,M. Arenz, Journal of Power Sources 2014, 261, 14; L. Li; L. P. Hu; J. Li,Z. D. Wei, Nano Res 2015, 8, 418.

[5] Y. Luo,N. Alonso-Vante, Electrochimica Acta 2015, 179, 108.

[6] V. R. Stamenkovic; B. Fowler; B. S. Mun; G. Wang; P. N. Ross; C. A. Lucas,N. M. Markovic, Science 2007; L. Gan; C. Cui; M. Heggen; F. Dionigi; S. Rudi,P. Strasser, Science 2014, 346, 1502; M. Escudero-Escribano; P. Malacrida; M. H. Hansen4; U. G. Vej-Hansen; A. Velázquez-Palenzuela; V. Tripkovic; J. Schiøtz; J. Rossmeisl; I. E. L. Stephens,I. Chorkendorff, Science 2016, 352, 73.

[7] V. Beermann; M. Gocyla; E. Willinger; S. Rudi; M. Heggen; R. E. Dunin-Borkowski; M.-G. Willinger,P. Strasser, Nano Letters 2016, 16, 1719.

[8] Y. Shao; J. Liu; Y. Wang,Y. Lin, J. Mater. Chem. 2009, 19, 46; N. F. Zheng,G. D. Stucky, Journal of the American Chemical Society 2006, 128, 14278.

[9] S.-Y. Huang; P. Ganesan; S. Park,B. N. Popov, JACS 2009.

[10] A. Lewera; L. Timperman; A. Roguska,N. Alonso-Vante, The Journal of Physical Chemistry C 2011, 115, 20153.

[11] V. T. Ho; C. J. Pan; J. Rick; W. N. Su,B. J. Hwang, J Am Chem Soc 2011, 133, 11716.

[12] A. Kumar,V. Ramani, Journal of the Electrochemical Society 2013, 160, F1207.

[13] A. Kumar,V. Ramani, ACS Catalysis 2014, 4, 1516.

[14] A. Kumar,V. K. Ramani, Applied Catalysis B: Environmental 2013, 138-139, 43; C.P. Lo,V. Ramani, ACS Applied Materials \& Interfaces 2012, 4, 6109; C.-P. Lo; G. Wang; A. Kumar,V. Ramani, Applied Catalysis B: Environmental 2013, 140-141, 133; J. Parrondo; T. Han; E. Niangar; C. Wang; N. Dale; K. Adjemian,V. Ramani, Proc Natl Acad Sci U S A 2014, 111,45 .

[15] M. L. Dou; M. Hou; D. Liang; W. T. Lu; Z. G. Shao,B. L. Yi, Electrochimica Acta 2013, 92, 468 .

[16] T. Tsukatsune; Y. Takabatake; Z. Noda; T. Daio; A. Zaitsu; S. M. Lyth; A. Hayashi,K. Sasaki, Journal of the Electrochemical Society 2014, 161, F1208.

[17] G. Cognard; G. Ozouf; C. Beauger; G. Berthomé; D. Riassetto; L. Dubau; R. Chattot; M. Chatenet,F. Maillard, Applied Catalysis B: Environmental 2017, 201, 381.

[18] Y. Liu,W. E. Mustain, J Am Chem Soc 2013, 135, 530; S. Zhao; A. E. Wangstrom; Y. Liu; W. A. Rigdon,W. E. Mustain, Electrochimica Acta 2015, 157, 175.

[19] Y. Liu,W. E. Mustain, Electrochimica Acta 2014, 115, 116.

[20] G. Wang; K. Bhattacharyya; J. Parrondo,V. Ramani, Chemical Engineering Science 2016, 154,81 . 


\section{WILEY-VCH}

[21] A. Cuesta; A. Couto; A. Rincón; M. C. Pérez; A. López-Cudero,C. Gutiérrez, Journal of Electroanalytical Chemistry 2006, 586, 184; A. López-Cudero; Á. Cuesta,C. Gutiérrez, Journal of Electroanalytical Chemistry 2006, 586, 204; F. Maillard; M. Eikerling; O. V. Cherstiouk; S. Schreier; E. Savinova,U. Stimming, Faraday Discussions 2004, 125, 357; D. F. van der Vliet; C. Wang; D. G. Li; A. P. Paulikas; J. Greeley; R. B. Rankin; D. Strmcnik; D. Tripkovic; N. M. Markovic,V. R. Stamenkovic, Angew Chem Int Edit 2012, 51, 3139.

[22] S. Rudi; C. Cui; L. Gan,P. Strasser, Electrocatalysis 2014, 5, 408.

[23] S. Cherevko; A. R. Zeradjanin; G. P. Keeley,K. J. J. Mayrhofer, J Electrochem Soc 2014, 161, H822.

[24] W. Ostwald, Zeitschrift für Physikalische Chemie 1897, 22, 289.

[25] L. Wang; F. Dionigi; N. T. Nguyen; R. Kirchgeorg; M. Gliech; S. Grigorescu; P. Strasser,P. Schmuki, Chemistry of Materials 2015, 27, 2360.

[26] H. Borchert; E. V. Shevehenko; A. Robert; I. Mekis; A. Kornowski; G. Grubel,H. Weller, Langmuir 2005, 21, 1931

[27] U. Diebold, Surface Science Reports 2003, 48, 53; Q. Fu,T. Wagner, Surface Science Reports 2007, 62, 431; Q. Fu; T. Wagner; S. Olliges,H. D. Carstanjen, J Phys Chem B 2005, 109, 944; V. A. O'Shea; M. C. Galvan; A. E. Prats; J. M. Campos-Martin,J. L. Fierro, Chem Commun (Camb) 2011, 47, 7131; M. Yoshida; K. Takanabe; K. Maeda; A. Ishikawa; J. Kubota; Y. Sakata; Y. Ikezawa,K. Domen, J Phys Chem C 2009, 113, 10151; S. Bonanni; K. Aït-Mansour; H. Brune,W. Harbich, ACS Catalysis 2011, 1, 385; M. G. Willinger; W. Zhang; O. Bondarchuk; S. Shaikhutdinov; H. J. Freund,R. Schlogl, Angew Chem Int Edit 2014, 53, 5998; X. Y. Shi; W. Zhang; C. Zhang; W. T. Zheng; H. Chen,J. G. Qi, J Microsc-Oxford 2016, 262, 203; C. Spoeri; J. T. Kwan; A. Bonakdarpour; D. Wilkinson,P. Strasser, Angew Chem Int Ed Engl 2016; F. Micoud; F. Maillard; A. Bonnefont; N. Job,M. Chatenet, Phys Chem Chem Phys 2010, 12, 1182.

[28] F. Dionigi; P. C. K. Vesborg; T. Pedersen; O. Hansen; S. Dahl; A. Xiong; K. Maeda; K. Domen,I. Chorkendorff, Journal of Catalysis 2012, 292, 26.

[29] R. Rizo; M. J. Lázaro; E. Pastor,M. T. M. Koper, ChemElectroChem 2016.

[30] K. Kakinuma; Y. Chino; Y. Senoo; M. Uchida; T. Kamino; H. Uchida; S. Deki,M. Watanabe, Electrochimica Acta 2013, 110, 316.

[31] M. Nakada; A. Ishihara; S. Mitsushima; N. Kamiya,K. Ota, Electrochem Solid St 2007, 10, F1.

[32] M. C. Santos,L. O. S. Bulhoes, Electrochimica Acta 2003, 48, 2607.

[33] H.-S. Oh; H. N. Nong; T. Reier; A. Bergmann; M. Gliech; J. Ferreira de Araújo; E. Willinger; R. Schlögl; D. Teschner,P. Strasser, Journal of the American Chemical Society 2016, 138, 12552.

[34] G. N. Vayssilov; Y. Lykhach; A. Migani; T. Staudt; G. P. Petrova; N. Tsud; T. Skala; A. Bruix; F. Illas; K. C. Prince; V. Matolin; K. M. Neyman,J. Libuda, Nat Mater 2011, 10, 310 .

[35] S. Rudi; L. Gan; C. H. Cui; M. Gliech,P. Strasser, Journal of the Electrochemical Society 2015, 162, F403.

[36] A. Thust; J. Barthel,K. Tillmann, Journal of large-scale research facilities JLSRF 2016, 2.

[37] A. Kovács; R. Schierholz,K. Tillmann, Journal of large-scale research facilities JLSRF 2016, 2.

[38] S. Cherevko; A. R. Zeradjanin; A. A. Topalov; G. P. Keeley,K. J. J. Mayrhofer, J Electrochem Soc 2014, 161, H501; A. K. Schuppert; A. A. Topalov; I. Katsounaros; S. O. Klemm,K. J. J. Mayrhofer, J Electrochem Soc 2012, 159, F670. 


\section{WILEY-VCH}

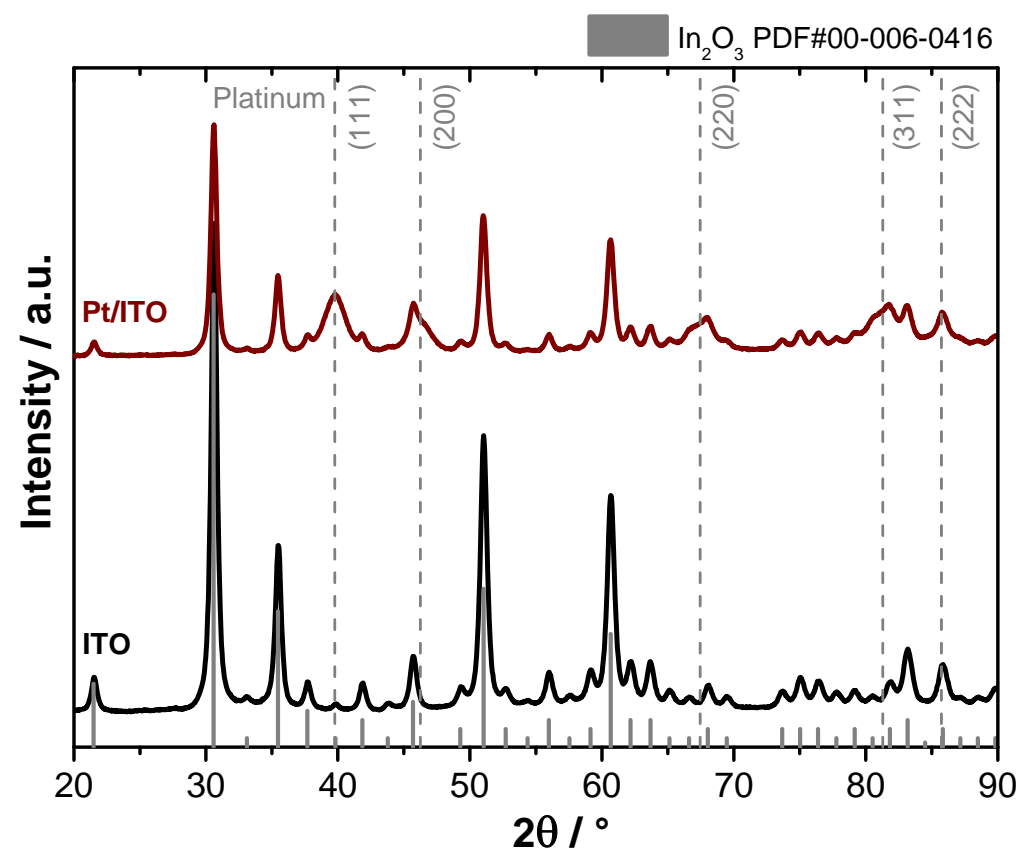

Figure 1. X-ray diffraction patterns of the bare ITO support material (black, bottom) and $\mathrm{Pt} / \mathrm{ITO}$ catalyst (dark red, top) obtained using $\mathrm{Cu} \mathrm{K}_{\alpha}$ radiation. Solid lines denote pure $\mathrm{In}_{2} \mathrm{O}_{3}$ reference pattern (PDF\#00-006-0416). Vertical dashed lines denote reference powder diffraction patterns of fcc Pt (PDF\#00-004-0802). 


\section{WILEY-VCH}
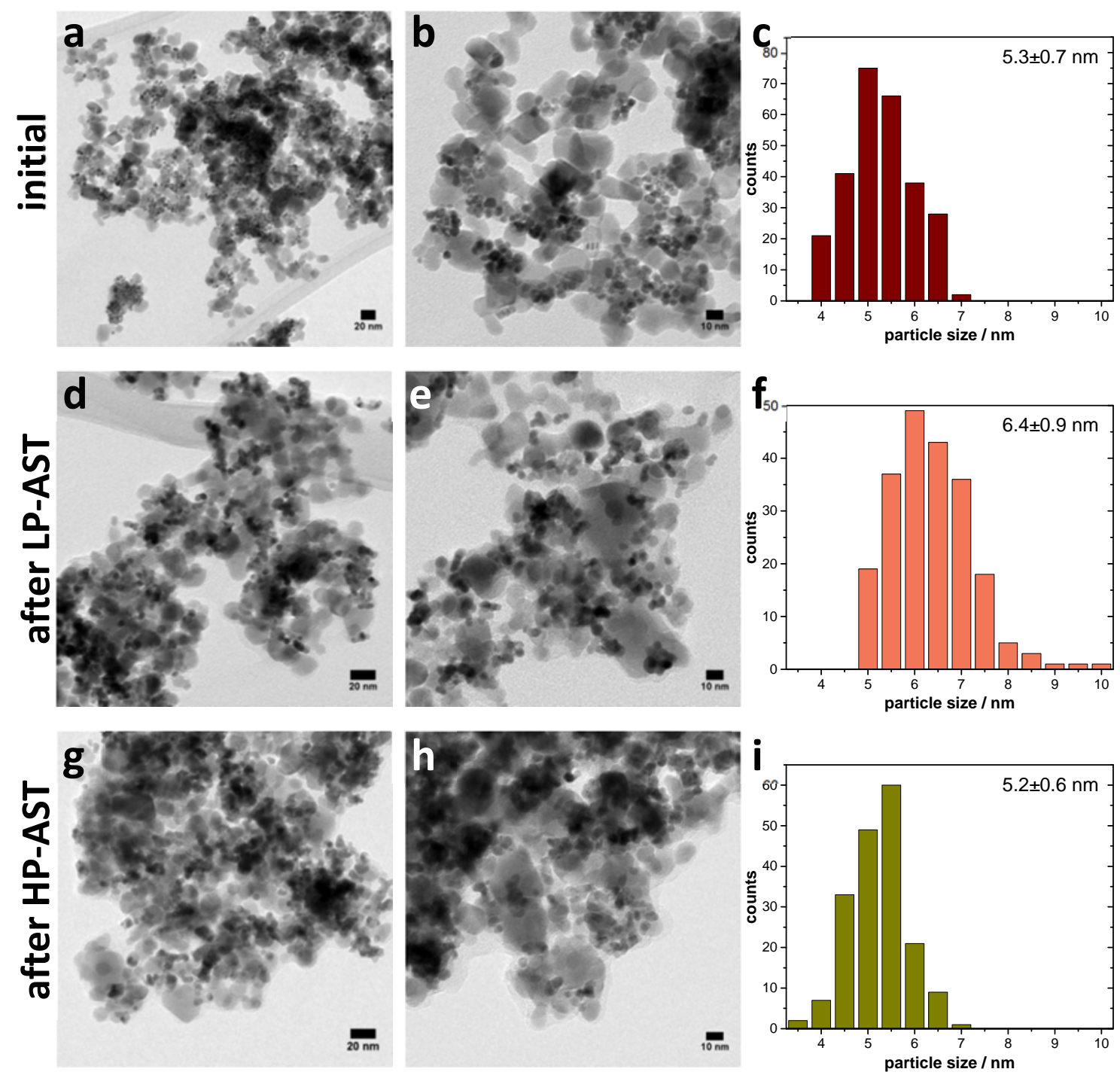

Figure 2. TEM images of the as prepared Pt nanoparticles on the ITO support $(a, b)$, after electrochemical cycling for $5 \mathrm{k}$ times in lower potential region $(\mathrm{d}, \mathrm{e})$ and in the higher potential region $(\mathrm{g}, \mathrm{h})$ as well as the corresponding histograms showing the particle size distribution (c,f,i). Histograms were obtained by measuring the diameter of at least 200 particles with errors obtained from standard deviation of mean particle diameter. 


\section{WILEY-VCH}
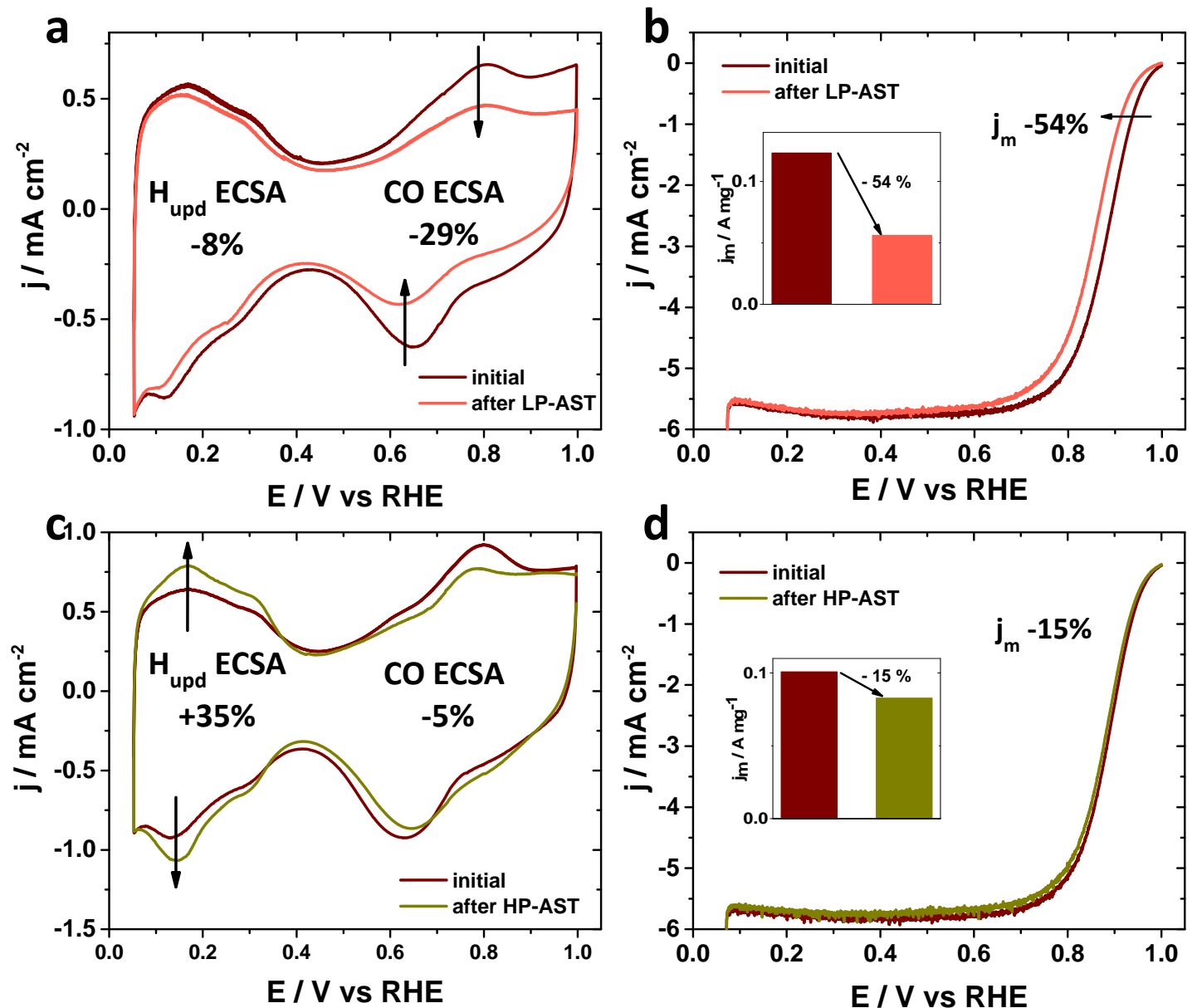

Figure 3. Cyclic voltammograms of Pt/ITO catalyst before and after potential cycling in lower (a) and higher (c) potential region. CVs were recorded in nitrogen saturated electrolyte from $0.05-1 \mathrm{~V}$ with a scan rate of $100 \mathrm{mV} \mathrm{s}^{-1}$. Figure $\mathrm{b}$ and $\mathrm{d}$ are showing LSVs of the particular states with the bar plots in the inlets representing the mass activity $\left(\mathrm{j}_{\mathrm{m}}\right)$ evaluated at $0.9 \mathrm{~V}$. LSVs were recorded in oxygen-saturated electrolyte from $0.05-1 \mathrm{~V}$ with a scan rate of $5 \mathrm{mV} \cdot \mathrm{s}^{-1}$ and $1600 \mathrm{rpm}$. All electrode potentials have been corrected for iR drop. 


\section{WILEY-VCH}

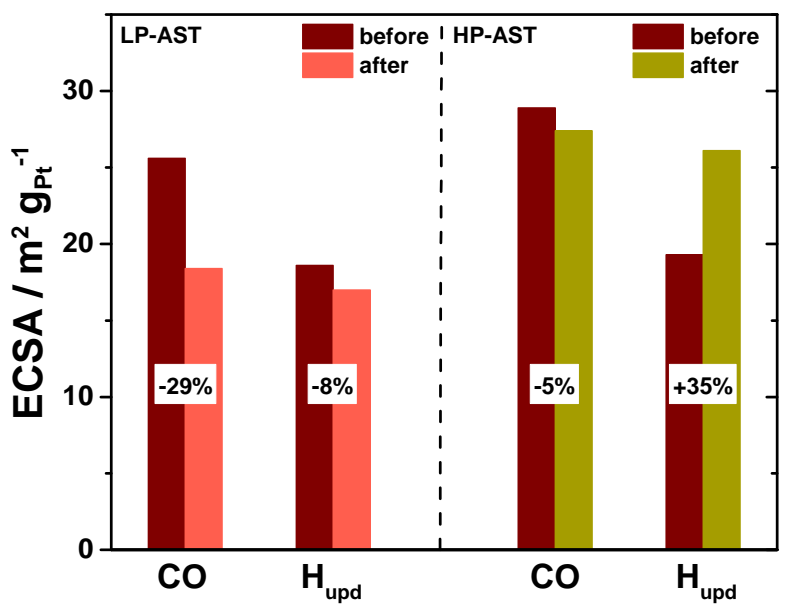

Figure 4. Comparison of ECSAs based on the integration in the $\mathrm{H}_{\mathrm{upd}}$ and the $\mathrm{CO}$ oxidation potential range. CO-ECSAs were determined by integrating the $\mathrm{CO}$ oxidation peak area from the first cycle of the $\mathrm{CO}$ stripping experiment after subtraction of the

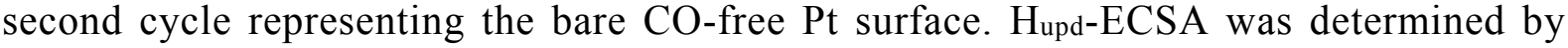
subtracting the first from the second cycle of the $\mathrm{CO}$ stripping experiment.
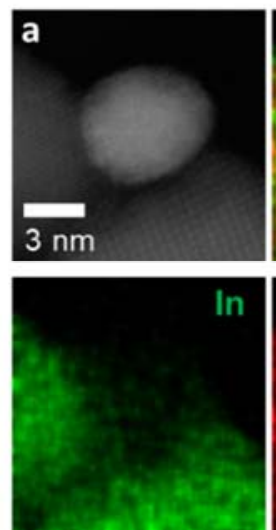
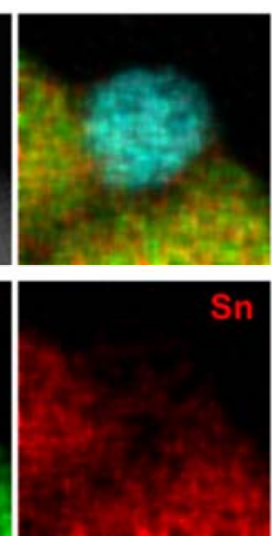
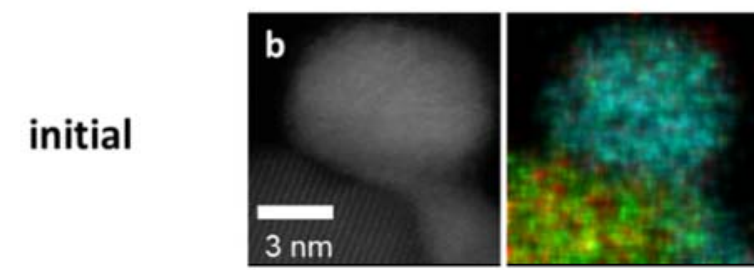

after LP-AST
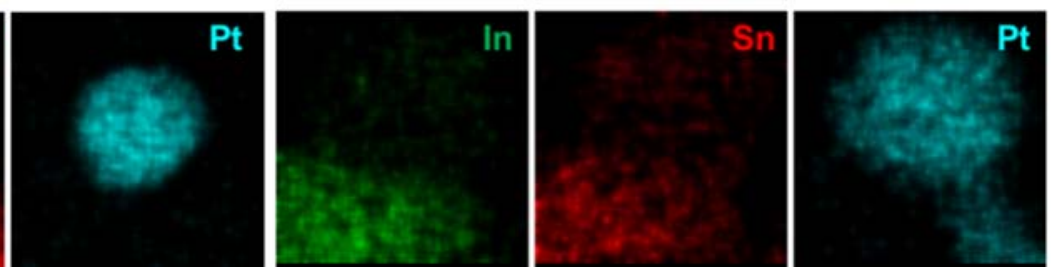

Pt

Figure 5. HAADF-STEM images and EDX mapping of Pt/ITO initial (a) and after LPAST (b). Platinum is depicted in light blue, Indium in green and Tin in red. 


\section{WILEY-VCH}
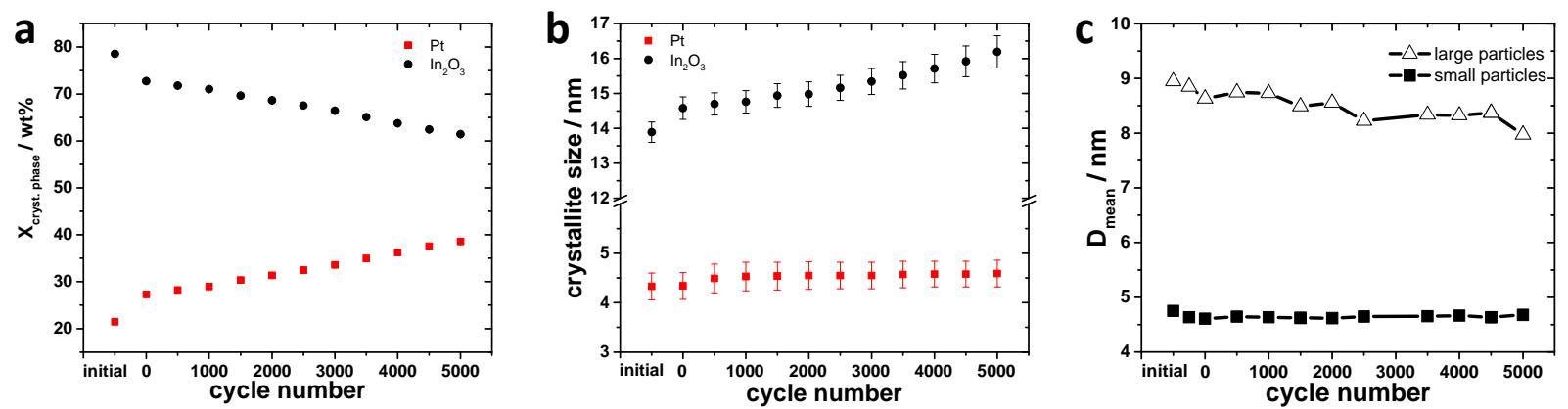

Figure 6. In situ HE-XRD and ASAXS measurements for LP-AST. Weight fractions of crystalline phases (a) and their coherence lengths (b) as determined by Rietveld Refinement. Mean Pt particle diameter (c) was determined from fitting of ASAXS curves.
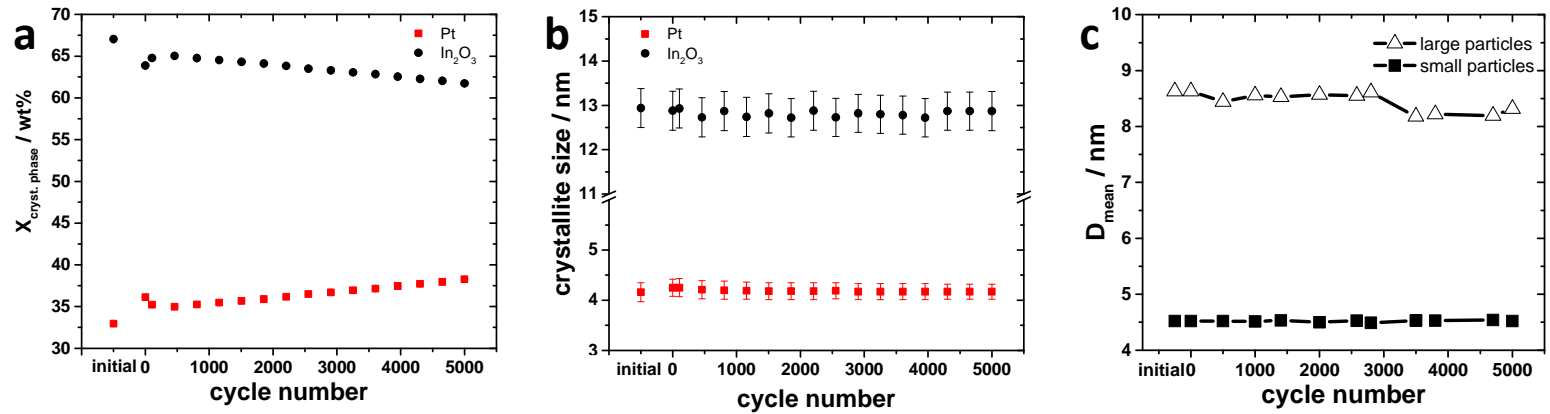

Figure 7. In situ HE-XRD and ASAXS measurements for HP-AST. Weight fractions of crystalline phases (a) and their coherence lengths (b) as determined by Rietveld Refinement. Mean Pt particle diameter (c) was determined from fitting of ASAXS curves. 
WILEY-VCH

a

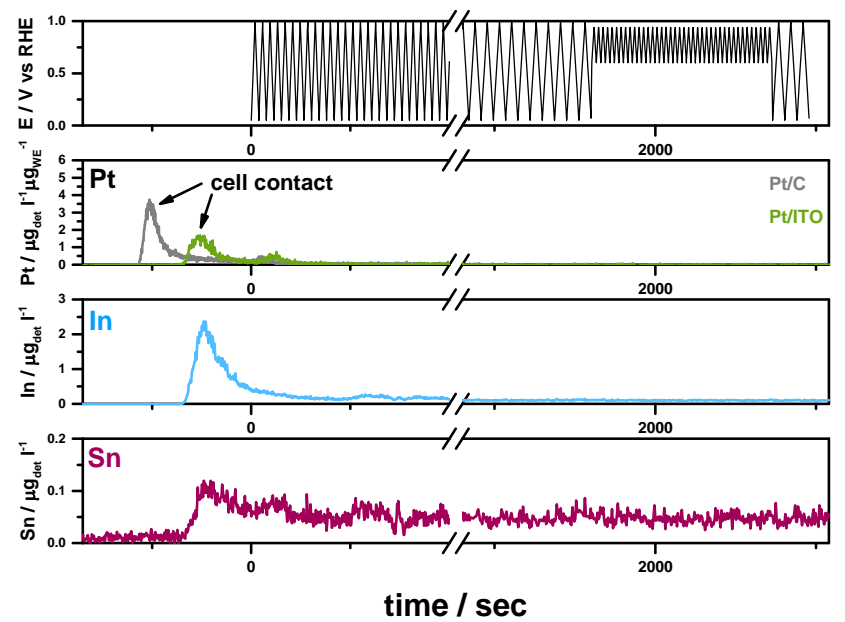

b

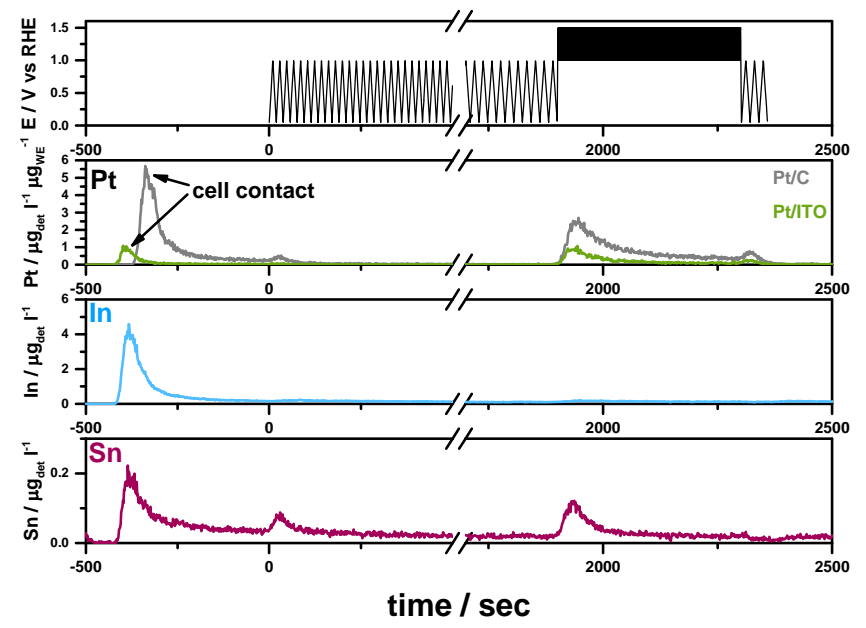

Figure 1. In situ scanning flow cell ICP-MS measurements. Depicted are the $\mathrm{Sn}$, In and Pt dissolutions rates and the applied electrochemical protocols from the bottom to the top for (a) LP-AST and (b) HP-AST. The respective dissolution rates in detected (det) metal in $\mu \mathrm{g}$ per volume electrolyte $\left(\mu g_{\text {det }} l^{-1}\right)$ are plotted against the time. A Pt/C reference sample was measured and therefore, the $\mathrm{Pt}$ dissolution rate was also normalized to the $\mathrm{Pt}$ mass loading on the working electrode (WE) $\left(\mu \mathrm{g}_{\mathrm{det}} 1^{-1} \mu \mathrm{g}_{\mathrm{WE}}{ }^{-1}\right)$. The electrochemical protocol was conducted as follows: Beginning with $100 \mathrm{CVs}$ (activation regime) from 0.05-1 V, followed by potential cycling in the LP regime $\left(0.6-0.95 \mathrm{~V}, 40 \mathrm{CVs}, 100 \mathrm{mV} \cdot \mathrm{s}^{-1}\right)$ or in the HP regime $\left(1.0-1.5 \mathrm{~V}, 200 \mathrm{CVs}, 500 \mathrm{mV} \cdot \mathrm{s}^{-1}\right)$ and followed by another 3 cycles from 0.05 $1 \mathrm{~V}$, all CVs were recorded with a scan rate of $100 \mathrm{mV} / \mathrm{s}$. The first contacts between catalyst and electrolyte (cell contact) are denoted with arrows. Breaks at the time axis of a and $\mathrm{b}$ have been implemented between 500 and $1700 \mathrm{~s}$. Graphs with complete time axis can be found in supporting information (Figure S9 and S10).

Table 1. Near-surface composition of Pt/ITO before and after LP-AST in the lower potential regime as obtained from XPS measurements. The molar ratios $\mathrm{Pt}$, In and $\mathrm{Sn}$ were determined from the peak areas of the Pt $4 \mathrm{f}$ as well as In and $\mathrm{Sn} 3 \mathrm{~d}$ spectra recorded with a kinetic energy of the photoelectrons of $550 \mathrm{eV}$. The number in brackets denotes the composition at a second beam position of each sample.

\begin{tabular}{|c|c|c|}
\hline & $\mathrm{Pt} /(\mathrm{In}+\mathrm{Sn})$ & $\mathrm{Sn} / \mathrm{In}$ \\
\hline initial & $0.2(0.21)$ & $0.17(0.17)$ \\
\hline after LP-AST & $0.25(0.27)$ & $0.14(0.13)$ \\
\hline
\end{tabular}




\section{WILEY-VCH}

In situ Scattering and spectroscopy reveals degradation mechanisms of ITO supported

Pt fuel cell electrocatalyst. Monodisperse ITO supported Pt nanoparticles show excellent morphological stability during stress tests, oxide migration partially blocks active Pt sites causing activity losses. Degradation mitigation is achieved by slight Pt dissolution inhibiting surface modification.

Keywords: oxide supported platinum, oxygen reduction reaction, nanoparticle, in situ X-ray, catalyst degradation

Henrike Schmies ${ }^{1}$, Arno Bergmann ${ }^{1}$, Jakub Drnec ${ }^{2}$, Guanxiong Wang ${ }^{3}$, Detre Teschner ${ }^{4,5}$, Stefanie Kühl ${ }^{1}$, Daniel Sandbeck ${ }^{6}$, Serhiy Cherevko ${ }^{6}$, Martin Gocyla ${ }^{7}$, Meital Shviro ${ }^{7}$, Marc Heggen $^{7}$, Vijay Ramani ${ }^{3}$, Rafal Dunin-Borkowski ${ }^{7}$, Karl J.J. Mayrhofer ${ }^{6}$, Peter Strasser ${ }^{1 *}$

\section{Unravelling Degradation Pathways of Oxide-supported Pt Fuel Cell Nanocatalysts under in situ Operating Conditions}

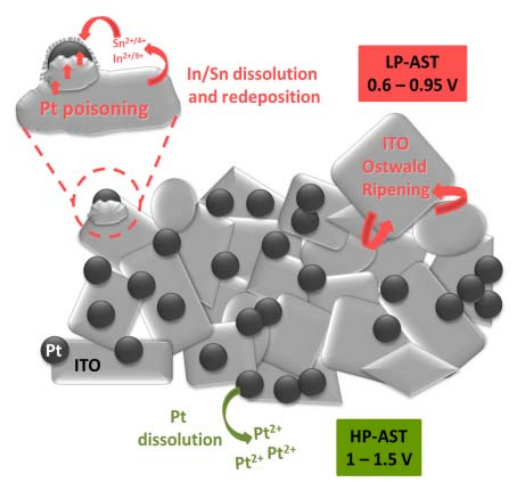

Copyright WILEY-VCH Verlag GmbH \& Co. KGaA, 69469 Weinheim, Germany, 2016. 